\title{
Quantifying the effect of riming on snowfall using ground-based observations
}

\author{
Moisseev, Dmitri
}

2017-04-16

Moisseev , D , von Lerber , A \& Tiira , J 2017 , ' Quantifying the effect of riming on snowfall using ground-based observations ', Journal of Geophysical Research : Atmospheres, vol. 122 , no. 7 , pp. 4019-4037 . https://doi.org/10.1002/2016JD026272

http://hdl.handle.net/10138/185423

https://doi.org/10.1002/2016JD026272

acceptedVersion

Downloaded from Helda, University of Helsinki institutional repository.

This is an electronic reprint of the original article.

This reprint may differ from the original in pagination and typographic detail.

Please cite the original version. 


\title{
Quantifying the effect of riming on snowfall using ground-based observations
}

\author{
Dmitri Moisseev ${ }^{1,2}$, Annakaisa von Lerber ${ }^{2}$, Jussi Tiira ${ }^{1}$ \\ ${ }^{1}$ Department of Physics, University of Helsinki, Helsinki, Finland \\ ${ }^{2}$ Finnish Meteorological Institute, Helsinki, Finland
}

Key Points:

- Rime mass fraction and unrimed snow mass-size relation are derived

- Riming is responsible for $5 \%$ to $40 \%$ of snowfall mass

- Riming can either increase or decrease the differential reflectivity

Corresponding author: Dmitri Moisseev, Department of Physics, University of Helsinki, Gustaf Hälströmin Katu 2a, Helsinki, Finland., dmitri.moisseev@helsinki.fi 


\begin{abstract}
Ground based observations of ice particle size distribution and ensemble mean density are used to quantify the effect of riming on snowfall. The rime mass fraction is derived from these measurements by following the approach that is used in a single ice-phase category microphysical scheme proposed for the use in numerical weather prediction models. One of the characteristics of the proposed scheme is that the prefactor of a power-law relation that links mass and size of ice particles is determined by the rime mass fraction, while the exponent does not change. To derive the rime mass fraction a mass-dimensional relation representative of unrimed snow is also determined. To check the validity of the proposed retrieval method, the derived rime mass fraction is converted to the effective liquid water path that is compared to microwave radiometer observations. Since dual-polarization radar observations are often used to detect riming, the impact of riming on dual-polarization radar variables is studied for differential reflectivity measurements. It is shown that the relation between rime mass fraction and differential reflectivity is ambiguous, other factors such as change in median volume diameter need also be considered. Given the current interest on sensitivity of precipitation to aerosol pollution, which could inhibit riming, the importance of riming for surface snow accumulation is investigated. It is found that riming is responsible for $5 \%$ to $40 \%$ of snowfall mass. The study is based on data collected at the University of Helsinki field station in Hyytiälä during US DOE Biogenic Aerosols Effects on Clouds and Climate (BAECC) field campaign and the winter 2014/2015. In total 22 winter storms were analyzed and detailed analysis of two events is presented to illustrate the study.
\end{abstract}

\title{
1 Introduction
}

In mid- to high- latitudes majority of precipitation originates from snow [Field and Heymsfield, 2015]. Ice particles grow by vapor deposition, aggregation and riming. Riming is an important precipitation process, given that a large percentage of cloud systems contain supercooled liquid water [Hogan et al., 2003; Moss and Johnson, 1994]. Borys et al. [2003, 2000] have shown that in mid-latitude orographic clouds both riming and snowfall rates are affected by anthropogenic aerosol pollution. Saleeby et al. [2013] have further investigated this phenomenon and found that the local aerosol effect on snowfall can be significant, though synoptic conditions may have larger influence. Lohmann [2004] shown that the aerosol impact on riming could have climatic implications. Given this potential sensitivity of precipitation and climate, there is a need to quantify how important riming is for surface precipitation. Mitchell et al. [1990] and Harimaya and Sato [1989] have shown that riming could explain $30 \%$ to $100 \%$ of surface snowfall mass. Furthermore, Grazioli et al. [2015] have found that there is also an apparent positive correlation between a precipitation rate and riming occurrence during winter storms.

Typically riming is quantified either by using manual observations of individual snow particles [e.g., Mitchell et al., 1990; Harimaya and Sato, 1989; Mosimann et al., 1994] or by utilizing automatic optical observations [Garrett and Yuter, 2014; Grazioli et al., 2015]. From automatic optical observations riming is detected by identifying visual particle features that are caused by riming. For example, by visually inspecting rime coverage of an ice particle surface, Mosimann et al. [1994] introduced the degree of riming, a parameter that defines what part of the particle surface is covered by frozen drops. They have also shown a connection between the degree of riming and rime mass fraction, which is used in numerical weather prediction models.

Dual-polarization radar observations are often used to identify ice precipitation regions affected by riming [e.g., Straka et al., 2000; Liu and Chandrasekar, 2000; Chandrasekar et al., 2013; Giangrande et al., 2016]. Accurate identification of such regions would improve our understanding of precipitation processes as well as improve aviation safety [Ellis et al., 2012], among other applications. Unfortunately, the connection between dual-polarization 
radar observations and riming is not always unambiguous and further studies are needed to establish a better link.

Recently a new microphysical scheme based on a single ice-phase category was proposed for the use in numerical weather prediction models [Morrison and Grabowski, 2008; Morrison and Milbrandt, 2015]. This new microphysical scheme allows a continuous representation of changes of ice particle properties and avoids abrupt and artificial transition from one ice particle type to another. The scheme assumes that, during riming, particle maximum dimension stays the same, while mass increases [Heymsfield, 1982; Erfani and Mitchell, 2017]. The particle maximum dimension will eventually increase by riming, but this will happen at the graupel stage. Morrison and Grabowski [2008], Morrison and Milbrandt [2015] and Erfani and Mitchell [2017] have explained that this conceptual model would result in a power-low mass-dimensional relation, $m=\alpha D^{\beta}$, where the exponent, $\beta$, remains constant, while the prefactor, $\alpha$, increases. Therefore, the mass-dimensional relation can be written as a function of the rime mass fraction.

This paper presents analysis of 22 events observed during two consecutive winters, $2013 / 2014$ and 2014/2015. The assumption that only the prefactor of the $m(D)$ relation is reacting to riming is converted to a method to retrieve rime mass fraction from surface-based snowfall measurements. As a part of the developed method a mass-size relation that can be treated as representative of unrimed snowflakes is also determined. The validity of the proposed retrieval method is checked by estimating particle effective liquid water paths that correspond to the computed rime mass fractions and comparing these to microwave radiometer observations. Furthermore, the computed rime mass fraction in combination with precipitation rate and accumulation observations are used to quantify impact of riming on precipitation mass. Finally, the impact of riming on dual-polarization radar variables is investigated.

\section{Data and Methods}

\subsection{Observations}

This study is based on observations carried out during the Biogenic Aerosols Effects on clouds and Climate (BAECC) field experiment [Petäjä et al., 2016] and the winter 2014/2015. During the experiment US Department of Energy Atmospheric Radiation Measurement (ARM) deployed the second ARM mobile facility (AMF2) to the University of Helsinki Research Station located in Hyytiälä Finland (61 $\left.50^{\prime} 37^{\prime \prime} \mathrm{N}, 24^{\circ} 17^{\prime} 16^{\prime \prime} \mathrm{E}\right)$. In addition to the remote sensing instruments of the AMF2, an extensive suite of surface-based precipitation instrumentation was placed at the measurement site $20-30 \mathrm{~m}$ away from the remote sensors. A part of the surface-based precipitation instrumentation is provided by the NASA Global Precipitation Mission Validation program.

Data from two AMF2 remote sensing instruments is used in this study. Microwave radiometer (MWR) retrieved liquid water path (LWP) [Cadeddu et al., 2013] is used to cross validate the derived rime mass fraction. High spectral resolution lidar (HSRL) observations of back scatter and linear depolarization ratio are employed for detection of embedded supercooled-liquid water layers [e.g., Hogan et al., 2003; Shupe et al., 2006; Westbrook and Illingworth, 2011], which appear as thin bright layers in the backscatter coefficient measurements.

In addition to the AMF2 remote sensors, data from Finnish Meteorological Institute (FMI) C-band dual-polarization weather radar is employed in this study. The FMI radar, which is located in Ikaalinen about $64 \mathrm{~km}$ west of the measurement site, performed range height indicator scans over the measurement site every $15 \mathrm{~min}$. From these observations vertical profiles of reflectivity and differential reflectivity are computed. To compute these profiles, reflectivity and differential reflectivity measurements for each ray were averaged using range gates located within $1 \mathrm{~km}$ ground range of the measurement site. It should be noted 
that because of the availability of the range height indicator (RHI) scans quasi-vertical profiles [Ryzhkov et al., 2016] were not used.

The presented method and data analysis is based on observations of volume flux weighted ensemble mean density and particle size distribution parameters of falling snow. These observations started in December 2013 and being carried continuously since. The ensemble mean density is retrieved using particle volume flux computed from NASA Particle Imaging Package (PIP) and liquid water equivalent (LWE) precipitation rate measured by a weighing gauge [Tiira et al., 2016]. The particle size distribution (PSD) parameters are computed from PIP observations. Because the density retrieval is sensitive to precipitation accumulation, the PSD parameters and ensemble mean density values are retrieved from observations which were collected with a temporal resolution determined by the precipitation accumulation. It was required that the precipitation accumulation exceeds $0.1 \mathrm{~mm}$. This way it was insured that the retrieval error is minimized [Tiira et al., 2016]. The PSD parameters were computed using a standard technique, see [e.g., Bringi and Chandrasekar, 2001; Leinonen et al., 2012].

Prior to 24 November 2016, the date on which the PIP software was updated, the PIP diameter bin size was set to $0.25 \mathrm{~mm}$. After the date it was set to $0.2 \mathrm{~mm}$. This also affected the minimum recorded particle size, before the software update it was $0.25 \mathrm{~mm}$ and it became $0.2 \mathrm{~mm}$. Tiira et al. [2016] have shown the impact of the PSD truncation on the retrieved density. It is shown that for cases where the median volume diameter, $D_{0}$, is less than $1 \mathrm{~mm}$, the density is expected to be overestimated by at most $20 \%$. For larger $D_{0}$ cases this error becomes smaller than $5 \%$.

The PIP records video with $380 \mathrm{fps}$, which means that typically more than two observations of the same particle are recorded. From these records the particle fall velocity is computed. It should be noted that the number of records is determined not only by the vertical velocity of the particles, but also by horizontal wind. During all of our observations wind speeds did not exceed $4 \mathrm{~m} / \mathrm{s}$. The observed relation between the snow density and median volume diameter is shown in Fig. 1. The density and PSD parameters are derived from observations from winters of 2013/2014 and 2014/2015 as discussed in Tiira et al. [2016].

Since PIP records snowflake shadows on a single side plane only, the observed particle dimensions are not necessary matching the true ones [Wood et al., 2013; Tiira et al., 2016]. The PIP measured diameter is the equivalent area diameter, which is the diameter of a circle with the same area as the area of a particle shadow. Following Tiira et al. [2016], in this study the PIP observed diameter is converted to the volume equivalent diameter, $D_{\text {veq }}$, and to the maximum particle diameter $D_{\max }$. The conversion is done by applying a correction factor of $1 / 0.92$ for $D_{\text {pip }}$ to $D_{v e q}$ conversion. Tiira et al. [2016] found that this correction factor is suitable for the dataset used in this study and represents the average particle shape, which can be assumed to be spheroidal with the axis ratio , $A R$, of 0.6. The $D_{\max }$ is computed from the $D_{\text {veq }}$ as:

$$
D_{\max }=0.6^{-1 / 3} D_{\text {veq }} \text {. }
$$

This yields that $D_{\text {pip }} \approx 0.8 D_{\max }$, which is similar to what Wood et al. [2013] have derived.

There are two reasons why we assume that snowflakes can be modeled as spheroids with the axis ratio, $A R$, of 0.6 , which is a good model for mature snow aggregates as was shown by analyzing multi-frequency radar observations [Matrosov et al., 2005] and through theoretical studies of the aggregation process [Westbrook et al., 2004]. Firstly, the goal of this study is to investigate the connection between riming and snowfall accumulation. During the studied events, highest precipitation rates were recorded during the periods where relatively large snowflakes were observed. These snowflakes are typically aggregates or rimed 
aggregates. Secondly, as will be discussed later in the paper, the largest uncertainty in the rime mass fraction retrieval occurs during the cases where majority of precipitation occurs in the form of crystals. In these cases, the error caused by the assumption of the particle shape is relatively minor compared to the other error sources.

\subsection{Method}

A particle video-imager, such as the PIP, measures particle size distribution and fall velocity. These observations can be used to compute the particle volume flux. The volume flux in combination with precipitation rate measurements yield a bulk density [Brandes et al., 2007] or ensemble mean density of snow [Tiira et al., 2016]. It should be noted that the snow densities derived by Brandes et al. [2007] and Tiira et al. [2016] are the same, despite having different names. The notation, ensemble mean density, was adopted by Tiira et al. [2016] to be consistent with numerous aircraft studies, see for example [Heymsfield et al., 2004]. In these studies the notation bulk density is reserved for a density of individual ice particle and not to the mean density of a distribution of snowflakes.

Assuming that snow PSD can be represented in a Gamma functional form:

$$
N(D)=N_{0} D^{\mu} \exp (-\Lambda D)=N_{0} D^{\mu} \exp \left(-\frac{3.67+\mu}{D_{0}} D\right)
$$

where $N_{0}$ is the intercept parameter, $D_{0}$ is the median volume diameter and $\mu$ is the shape parameter; the particle volume flux, $F_{v}$, can be expressed as a function of PSD parameters, $N_{0}$ and $\Lambda$, and the parameters of a velocity-dimensional, $v(D)$, relation:

$$
\begin{array}{r}
F_{V}=\frac{\pi}{6} \int A R \cdot D^{3} \cdot a_{v} D^{b_{v}} \cdot N_{0} D^{\mu} \exp (-\Lambda D) \mathrm{d} D= \\
\quad=\frac{\pi}{6} \cdot A R \cdot a_{v} N_{0} \cdot \frac{\Gamma\left(4+b_{v}+\mu\right)}{\Lambda^{4+b_{v}+\mu}} \quad\left[\mathrm{cm} \mathrm{s}^{-1}\right],
\end{array}
$$

where $a_{v}$ and $b_{v}$ are the prefactor and exponent of the $v(D)$ relation. Here and later in the text $D$ stands for $D_{\max }$, therefore the particle axis ratio $A R$ is used to compute the volume. Following the same notation the precipitation rate, or the mass flux $F_{m}$, can be expressed as:

$$
\begin{gathered}
F_{m}=\int \alpha D^{\beta} \cdot a_{v} D^{b_{v}} \cdot N_{0} D^{\mu} \exp (-\Lambda D) \mathrm{d} D= \\
=\alpha a_{v} N_{0} \cdot \frac{\Gamma\left(\beta+b_{v}+\mu+1\right)}{\Lambda^{\beta+b_{v}+\mu+1}} \quad\left[\mathrm{~g} \mathrm{~cm}^{-2} \mathrm{~s}^{-1}\right]
\end{gathered}
$$

\footnotetext{
$\alpha D^{\beta}$.

This equation is derived expressing the mass-size relation in the power law form $m=$

Heymsfield [1982] have proposed a conceptual model that describes how ice particle properties evolve during riming. At the initial stage a particle, a planar ice crystal or an aggregate, is formed. The second stages, the first stage of riming growth, for the planar ice crystal and aggregate are different. The ice crystal growth mainly occurs by riming at the underside, which changes the aspect ratio of the particle while maintaining the maximum dimension. Given tumbling and gyration of aggregates, the aggregates grow by filing an imaginary spherical shell. At this stage the shell diameter is the particle maximum dimension, which stays constant. Both for the crystal and aggregate the second growth stage ends when the particles reach spherical shapes. At the last stage, the particles continue to grow in
} 
a spherical form and from this stage $D_{\max }$ starts to increase. This stage manifests beginning of the graupel growth stage.

We are proposing a small modification to this conceptual model. This modification concerns with the transformation of the aggregate shape during the second growth stage. We assume that the shape of an aggregate during this stage does not change. The riming just fills unoccupied places, while not affecting the snowflake shape, as summarized in Table 1. This assumption can be tested, since it has a direct implication for dual-polarization radar observations. It would mean that values of dual-polarization radar variables would increase due to riming, as will be presented later in more detail. As was discussed by Erfani and Mitchell [2017], Morrison and Grabowski [2008] and Morrison and Milbrandt [2015], snowflake growth during the first riming stage will lead to a snowflake mass-size relation where the exponent remains constant, while the prefactor changes. Therefore, the $m(D)$ relation can be written as a function of the rime mass fraction, $F R$, as:

$$
m=\alpha D^{\beta}=\frac{\alpha_{u s}}{1-F R} D^{\beta} \quad[\mathrm{g}]
$$

where $m_{u s}=\alpha_{u s} D^{\beta}$ is the mass-dimensional relation of unrimed snowflakes. The rime mass fraction is the ratio of the rime mass to the snowflake mass, $F R=m_{\text {rime }} / \mathrm{m}=$ $\left(m-m_{u s}\right) / m$. By combining (3), (4) and (5) and assuming the $F R$ is independent of size we can express the ensemble mean density as a function of the rime mass fraction:

$$
\rho=\frac{F_{m}}{F_{V}}=\frac{6}{\pi} \frac{\alpha_{u s}}{1-F R} \frac{\Gamma\left(\beta+b_{v}+\mu+1\right)}{A R \cdot \Gamma\left(4+\mu+b_{v}\right)} \Lambda^{3-\beta} \quad\left[\mathrm{g} \mathrm{cm}^{-3}\right]
$$

This leads to the expression of the rime mass fraction as a function of the retrieved ensemble mean snow density, $\Lambda$, the exponent of the $\mathrm{v}$-D relation and coefficients of the unrimed snow $m(D)$ relation.

$$
F R=1-\frac{6}{\pi} \cdot \frac{\alpha_{u s}}{\rho} \frac{\Gamma\left(\beta+b_{v}+\mu+1\right)}{A R \cdot \Gamma\left(4+\mu+b_{v}\right)} \Lambda^{3-\beta}
$$

The exponent of the $v(D)$ relation varies between 0.217 and 0.256 as was presented by Tiira et al. [2016]. However, the derived $F R$ values depend weakly on $b_{v}$. The $F R$ value changes by less than $1 \%$ due to changes in $b_{v}$. Therefore, $b_{v}$ can be assumed to be constant. It was selected to be equal to 0.22 . This value is close to what was found by Zawadzki et al. [2010]. To derive the rime mass fraction, given observations of $\rho$ and $\Lambda$, parameters $\alpha_{u s}$ and $\beta$ have to be estimated.

Using observations from two winters the ensemble mean snow density and median volume diameter were estimated [Tiira et al., 2016]. The scatter-plot between the two is shown in Fig. 1. From these observations a mass-size relation of unrimed snow is defined as follows. It is assumed that snow particles with the smallest mass for a given diameter represent unrimed snow. This means, that the lowest edge of the scatter plot, Fig. 1 should correspond to unrimed snow. To take into account possible uncertainties in the retrievals of $\rho$ and $D_{0}$, we have split the data into $D_{0}$ intervals ranging between 0.1 and $0.6 \mathrm{~cm}$ with a step of 0.02 $\mathrm{cm}$. For each interval, data that have density values belonging to the lowest $5 \%$ were selected. Using equation (6), where $F R=0$, the parameters of the mass-dimensional relation were estimated using a linear fit in the $\log \rho-\log D_{0}$ space. It was found that the relation $m=0.0075 D_{v e q}^{2.05}$, or $m=0.0053 D_{\max }^{2.05}$ if expressed as a function of $D_{\text {max }}$, represents the unrimed snow. It should be noted that the assumed value of $b_{v}$ has a negligible error on 
the retrieved relation. Tiira et al. [2016] have discussed impact of PSD truncation on the retrieval of $\rho$. This discussion also applies here. It was found that for $D_{0}$ values larger than 0.1 $\mathrm{cm}$ the bias in the computed ensemble mean density values, due to the small size truncation of PSD [Moisseev and Chandrasekar, 2007], is less than 5\%. Therefore it is expected that the derived $m(D)$ overestimates unrimed snowflake masses by at maximum 5\%. Of course, there is a possibility that during collected observations that span over two winters no unrimed snowflakes were observed. This possibility is difficult to quantify, given the lack of other supporting observations.

The comparison of the derived $m(D)$ to other relations presented in Fig. 1 show a relatively good agreement. The derived relation represent heavier ice particles than those observed by Brown and Francis [1995], for example. It can be seen in Fig. 1 that the vast majority of our observations are located above Brown and Francis [1995] curve. The relation found by Heymsfield et al. [2004], on the other hand, is very close.

To assess the potential uncertainty associated with the selection of the unrimed snow $m(D)$ relation, a comparison of relations reported in literature is performed and summarized in Fig. 2. The figure shows $m(D)$ relations for crystals (P1e, P1a, P1c, C1h according to Magono and Nakamura [1965] classification) [Pruppacher and Klett, 1996], early aggregates (P1e and P1a) [Kajikawa, 1989], lump graupel [Locatelli and Hobbs, 1974], aggregates of planar polycrystals and aggregates of side planes [Mitchell, 1996], aggregates of unrimed assemblages of dendrites [Locatelli and Hobbs, 1974] and relations of [Brown and Francis, 1995; Heymsfield et al., 2004]. If the relations for different particle types are considered separately, the biggest spread of masses for a given $D_{\max }$ is given by crystals. The masses of aggregates fall within a much narrow range of values shown by the dark gray shaded region. The Brown and Francis [1995] curve (dark blue solid line) falls well within this region, while our relation depicted by the black line and Heymsfield et al. [2004] relation (dark blue dashed line) can be considered as the upper boundaries of the aggregate region. The boundaries of this ad hoc region, can be given by the prefactor values of $m(D)$, which vary between 0.0024 and 0.0053 . Here we are assuming that $\beta=2.05$.

This analysis indicates that if the proposed relation for unrimed snow is used and riming is detected, i.e. FR is larger than zero, then there is a very high probability that riming actually occurs. The amount of riming may be underestimated. Since higher precipitation rates are typically associated with larger particles, in stratiform precipitation systems these particles are mainly aggregates at various stages of riming. In these cases the retrieval uncertainty is contained to the range of $\alpha$ values defined by the aggregation region.

Given the derived mass-dimensional relation for the unrimed snow and utilizing equation (7) the observed spread in the $\rho-D_{0}$ scatter plot can be explained in terms of the rime mass fraction. For example, the $\rho-D_{0}$ relation proposed by Brandes et al. [2007] matches well with the relation derived using $m_{u s}(D)$ and $F R=0.2$, as shown by the blue diamonds in Fig. 1. In a similar way, observations collected during BAECC campaign match well with $F R=0.45$ curve. The snow during winter 2014/2015 was less dense, $F R=0.3$, and closer to the one recorded in Colorado by Brandes et al. [2007]. The maximum observed value measured during our observation period lies in the range between 0.7 and 0.8 .

To summarize, the proposed method can be presented as the following steps:

1. At the first step, the ensemble mean density should be retrieved from observations of PSD, $v(D)$ and snowfall rate, $S R$, as described in [Tiira et al., 2016] or [Brandes et al., 2007]

2. At the second step, a mass-dimensional relation of unrimed snow should be estimated for a given climate or geographical location. This step can be potentially omitted and the relation $m_{u s}=0.0053 D_{\max }^{2.05}$ derived in this study can be used instead.

3. At the third step, the retrieved mean density, $m_{u s}(D), \mu, \Lambda$ and the exponent of $v(D)$ relation are applied to equation 7 to retrieve the rime mass fraction. It should be noted, 
that changes in $\mu$ and the exponent of $v(D)$ values have a minor effect on $F R$. They can be fixed to be 0 and 0.22 respectively, without making a significant error.

\section{Results}

\subsection{Case Studies}

\subsubsection{February 21, 2014}

To demonstrate how the retrieved rime mass fraction relates to the other falling snow microphysical parameters, analysis of two events is performed. The first analyzed snowfall case took place on 21 February 2014. A wide low pressure area from the North Atlantic was approaching Scandinavia with a trough and an associated frontal system passing over Hyytiälä from the southwest during the night of February 21-22. Around midnight UTC, the occlusion point of the system passed near the southwestern coast of Finland where also largest snow accumulations were recorded. In Fig. 3, time-series of PSD parameters, snowfall rate, the ensemble mean snow density and rime mass fraction are presented. Analysis of parts of this storm are already presented in literature [Kneifel et al., 2015; Petäjä et al., 2016; Kalesse et al., 2016]. Kneifel et al. [2015] have studied triple-frequency radar signatures and coinciding surface observations to infer a connection between multi-frequency radar and microphysical properties of snow. As a part of the presented analysis, it was found that around 2300 UTC there is a transition from light, graupel-like snowfall to a moderate aggregate snowfall. This transition is also clearly visible in Fig. 3. The $F R$ reaches 0.7 at 2305 UTC, meaning that $70 \%$ of the particle mass is determined by collected super-cooled liquid drops. This indicates very heavy riming. At the same time $D_{0}$ value is not very high, $0.15 \mathrm{~cm}$, that is a characteristic value for relatively small ice particles. Just a few minutes later, $D_{0}$ value doubles and at the same time the liquid water equivalent (LWE) precipitation rate exceeds $3 \mathrm{~mm} / \mathrm{h}$. During this period, which ends at around 2350 UTC, the retrieved rime mass fraction value drops below 0.5 and at some instances it goes below 0.2. At the same time there is also a reduction in Doppler velocity values, at the low levels, which also supports the idea of lower $F R$ values. After 2350 UTC the $F R$ increases again.

This short period of relatively heavy snowfall and lower $F R$ values coincides with ice phase seeder-feeder process [Hobbs, 1978; Matejka et al., 1980] discussed in [Petäjä et al., 2016] and can be seen in Fig. 4. The ice particles falling out of the cirrus cloud seed lower clouds, where riming is taking place. The evidence of riming is reported in [Kalesse et al., 2016], who have used a combination of radar Doppler spectra, microwave radiometer and riming model to analyze a part of this event. The intensive seeder-feeder process depletes super-cooled water and almost halts riming. The HSRL measured backscatter coefficient, presented in Fig. 4, shows smaller values during this period supporting the conclusion that the liquid layer is depleted. At the same time, aggregation growth of snowflakes becomes more active [Moisseev et al., 2015; Hobbs et al., 1974]. The seeding stops just before 0 UTC, as can be seen in Fig. 4, and the super-cooled water starts to restore and riming replaces aggregation as the dominating snow growth process.

Before the discussed period, the rime mass fraction was steadily increasing starting from 1900 UTC. It should be noted that between 2130 and 2305 UTC, the shaded area in Fig. 3, the precipitation rate was rather low and the density retrieval was unreliable. Because of this, the $F R$ values are also unreliable, and the values presented in the figure are just a linear interpolation between the values retrieved immediately before and after the abovementioned period. It should be noted that most of the precipitation accumulation during this event between 2300 and 0000 UTC, when aggregation was taking place. 


\subsubsection{March 20, 2014}

The second case study is of the snowfall event that took place on 20 March 2014. The total precipitation accumulation during this event is $4.3 \mathrm{~mm}$. The event is a textbook example of a typical winter precipitation event in Southern Finland, where similarly to the 21 February event, there is a wide low pressure area approaching Scandinavia from the west, and an associated frontal system passes over the Gulf of Finland from the southwest. The heaviest snowfall in Hyytiälä originated from the thick cloud area associated with a warm front reaching the area in the evening.

In Fig. 5 the summary of derived snow microphysical properties is shown. As can be seen the ensemble mean snow density varies between 0.1 and $0.3 \mathrm{~g} / \mathrm{cm}^{3}$. In many cases the high values are reached during the time periods when the median volume diameter approaches $0.1 \mathrm{~cm}$. Furthermore, the low density values coincide with periods when relatively large snowflakes are observed. This pattern is the same for the previously discussed event. The rime mass fraction values do not exhibit a correlation with $D_{0}$. This mean density behavior is not surprising, since it is not only the function of $F R$ but also of $D_{0}$

The radar and lidar observations recorded during this event are presented in Fig. 6. The KAZR vertical Doppler velocity show particle fall velocities ranging from 1.5 to $2 \mathrm{~m} / \mathrm{s}$ between 1730 and 1830 UTC and after 1900 UTC. These velocities indicate that the snowflakes observed during these periods are rimed [Mosimann, 1995; Barthazy and Schefold, 2006]. The rime mass fraction shows a local maximum of 0.2 starting just before 1630 and lasting until 1720 UTC, after which FR decreases to zero. At 1800 UTC the FR starts to increase again and continues until the end of the event, where it reaches the value of 0.7 . The comparison of $F R$ and Doppler velocity indicates that even though both observations indicate presence of rimed particles at about the same times, these times don't match exactly.

\subsection{Connection Between FR and LWP}

The proposed retrieval procedure relies on the assumption that differences in snowflake masses for particles of the same dimensions are due to different rime mass fractions. This assumption explicitly ignores possible changes in a particle mass linked to presence of different crystal habits, the associated uncertainty is discussed in the Section 2 . To test how viable this approximation is, a connection between derived $F R$ and another measurable quantity needs to be established. Given the rime mass is determined by the mass of swept supercooled liquid droplets, $F R$ can be expressed as a function of the effective liquid water path, $E L W P$, which can be written as:

$$
\begin{aligned}
E L W P=\frac{m_{\text {rime }}}{E_{r}(\pi / 4) D_{\max }^{2}} & =\frac{\alpha_{u s} D_{\max }^{\beta}}{E_{r}(\pi / 4) D_{\max }^{2}} \cdot \frac{F R}{1-F R} \approx \\
& \approx \frac{4}{\pi} \alpha_{u s} \frac{F R}{1-F R}\left[\mathrm{~g} \mathrm{~cm}^{-2}\right]
\end{aligned}
$$

where $m_{\text {rime }}$ is the change in the particle mass due to riming and $E_{r}$ is the riming efficiency. The final equation is derived assuming that $E_{r}=1$. It is known that $E_{r}$ is likely to vary considerably depending on cloud conditions, which may account for some discrepancies between $E L W P$ and $L W P$ values, which will be shown later. Also it is assumed that the area perpendicular to the direction of fall is circular, which is a reasonable approximation for planar crystals and aggregates. Given that the exponent of $m(D)$ relation is very close to 2 , dependence of (8) on $D_{\max }$ is also ignored.

Following (8) ELWP values were computed for the two case studies. In Fig. 7 the ELWP is plotted for the 21-22 February 2014 event. For the comparison, LWP observations by the AMF2 MWR are also presented in the figure. Overall, the ELWP and $L W P$ agree rather well. The $E L W P$ is lower, but follows $L W P$, two curves raise and fall at about the same 
time. It is not surprising that the $E L W P$ is lower. Firstly, the actual $E_{r}$ is probably lower than 1. Secondly, the path of a falling particle is different from the vertical path used in MWR observations. This also explains why ELWP and $L W P$ curves sometimes behave differently, as for example before 2000 UTC. The difference in paths could also explain a slight temporal shift between the curves, that is clearly visible in areas of large $L W P$ gradients.

The observations of 20 March 2014 also show a relatively good agreement, as can be seen in Fig. 8. The temporal shift between the curves is larger in this case. It was found that if the $E L W P$ curve is shifted by 30 min the agreement with $L W P$ is much better. As in the February case $L W P$ and $E L W P$ are correlated. Not all features visible in the $L W P$ curve can be found in the $E L W P$. The temporal resolutions are different and paths that particles travel in atmosphere are expected to be different from the vertical. It should be noted that the applied temporal shift also improves the comparison with the radar observations, as was discussed in the previous section. It is interesting to see that $L W P$ values below or close to the MWR detection limit can produce detectable riming signatures as can be observed in Fig. 8 around 1700 UTC. There is a clear peak in $F R$ reaching 0.2 , but both $E L W P$ and $L W P$ values are smaller than $30 \mathrm{gm}^{-2}$. This indicates that for detection of riming a dual-channel MWR should be used with care.

A comparison of $F R, E L W P$ and $L W P$ was performed for all BAECC cases. The results of this comparison are presented in Fig. 9. As was noted from the case studies both $F R$ and $E L W P$ are related to $L W P$. The correlations between $E L W P$ and $L W P$ or $F R$ and $L W P$ are not very high, the presented scatter plots are rather wide. This is not surprising, however, since no temporal adjustments to match the observations were performed. Nonetheless, the presented analysis show that the derived rime mass fraction reacts to the changes in $L W P$ indicating that both represent same processes that take place in the cloud system. The computed $E L W P$ is about two times lower than $L W P$. It can also be seen that if $L W P$ values exceed 400 $\mathrm{gm}^{-2}$ then we can expect heavily rimed ice particles with rime mass fractions exceeding 0.6.

\subsection{Impact of Riming on Surface Precipitation}

From observations of two snow events that took place in Sierra Nevada mountains Mitchell et al. [1990] have found that riming is responsible for 30\% to $40 \%$ of accumulated snow mass. Harimaya and Sato [1989] estimate that this value is higher for the coastal region of Japan and ranges between $50 \%$ and $100 \%$. Grazioli et al. [2015] have shown that there seems to be a correlation between occurrence of riming and precipitation accumulation.

To analyze the impact of riming on snowfall, we have computed total precipitation accumulations, $A$, for the recorded 22 events and corresponding rime precipitation accumulation, $A_{F R}$. The total accumulation and rime precipitation accumulation are defined as:

$$
\begin{array}{r}
A=\sum_{j} S R_{j} \cdot \Delta T_{j} \\
A_{F R}=\sum_{j} F R_{j} \cdot S R_{j} \cdot \Delta T_{j}
\end{array}
$$

where $j$ stands for a time integration period during which PSD parameters, $S R$ and $F R$ are estimated and $\Delta T_{j}$ is the corresponding integration time.

In Fig. 10 the accumulations for all events are shown. The observations show that riming is an important factor and responsible for $5 \%$ to $40 \%$ of snow mass accumulation. The found rime precipitation accumulation fraction, $A_{F R} / A$, is in line with Mitchell et al. [1990] finding and is lower than found by Harimaya and Sato [1989]. There is also appears to be a tendency that the higher accumulation events have larger rime precipitation accumulations, for example events 15 and 7. There are exceptions as well, events 10,11, 17 and 22 have above average accumulations, close or exceeding $6 \mathrm{~mm}$, while having below average $A_{F R}$. 
The Pearson correlation coefficient between $A$ and $A_{F R}$ is 0.83 as shown in Fig. 11. It could be higher, if events like 10,11, 17 and 22 can be considered outliers, or it can be significantly lower if events like 15 and 7 are rare. Given that the conclusion whether presence of riming would enhance precipitation accumulation depends very much on a few events, it is too early to make a decisive statement. It should further be noted that the correlation between average precipitation rate, $A$ divided by the event duration, and $A_{F R} / A$ is much smaller. The Pearson correlation coefficient is just 0.33 , see Fig. 11 . This seem to point to the conclusion that riming does not enhance precipitation, at least in the Southern Finland.

\subsection{Riming and Dual-Polarization Radar Observations}

Dual-polarization radar variables depend on hydrometeor shape and refractive index [Bringi and Chandrasekar, 2001]. In case of an ice particle the refractive index is directly related to the particle density [Sihvola, 1999]. We should note that in the radar community the definition of particle density is different from the bulk density used in connection with aircraft studies. The particle density used to compute the particle refractive index and radar variables, is the mass of the particle divided by the volume of a prolate or oblate spheroid. The length of a spheroid major axis typically coincided with the particle maximum dimension. The minor axis are determined such that the spheroid closely approximates the particle shape, see [e.g., Hogan et al., 2012] for the discussion on how the spheroidal dimensions can be defined. The particle density defined in this way is typically larger than the bulk density, and can be used for computations of the particle refractive index.

During the fill-in stage of riming growth, see Table 1, the particle mass is increasing while the maximum dimension stays constant. If the particle shape is also not changing as was hypothesized to be the case for aggregates, the measured differential reflectivity, $Z_{d r}$, should increase as FR increases, see [Bringi and Chandrasekar, 2001, p. 63] for an explanation of the connection between the particle density and values of dual-polarization radar variables. On the other hand, if the particle becomes more spherical, as expected to be the case for crystals, the $Z_{d r}$ should decrease with an increase in $F R$. Therefore, dual-polarization radar observations can be used to test the conceptual model describing the evolution of particle shape during riming growth.

To test the conceptual model, Ikaalinen radar observations of reflectivity, $Z$, and differential reflectivity are compared to $F R$, mean snow density and computed differential reflectivity values for the two analyzed events. From the RHI measurements that are performed every 15 min, a time-series of vertical profiles (VPT) of reflectivity and differential reflectivity above the measurement site were constructed. Both the reflectivity factor and differential reflectivity values were averaged over $1 \mathrm{~km}$ range. Time-series of $Z$ and $Z_{d r}$ values were also computed from observations of PSD and FR. To compute the radar variables Leinonen [2014] implementation of T-matrix code [Mishchenko and Travis, 1994; Wielaard et al., 1997] is utilized. Since the dual-polarization radar observations are sensitive to particle aspect ratios, $A R$, the computation are performed for various $A R$ values.

In Fig. 12 VPT observations of reflectivity and differential reflectivity for the 20 March 2014 event are shown. From the lowest reliable altitude, which is about $500 \mathrm{~m}$ above the ground, time-series of measured $Z$ and $Z_{d r}$ values are selected. These values are then compared to the computed ones as shown in Fig. 13. It can be seen that the computed and measured reflectivity values agree rather well. In this case, the computed reflectivity values did not change much with $A R$ and the ones computed using $A R=0.6$ are shown. The differential reflectivity, as expected, react strongly to changes in $A R$. In the figure two curves with $A R$ of 0.4 and 0.6 are shown. Between 1600 and 1800 UTC, the $Z_{d r}$ curve computed with $A R=0.4$ agrees better with the measurements. Between 1800 and 2000 UTC the 0.6 curve is in better agreement with the data. During this time the $F R$ was steadily increasing from 0.1 to 0.5 , while at the same time $Z_{d r}$ has also increased. The $Z_{d r}$ computations show that this increase in $Z_{d r}$ is due to the change in density, which is partially caused by the change 
in $F R$. Furthermore, the computations show that the particle shape stays constant during this time. This observation supports the conceptual model of riming growth of snow aggregates.

A different story can be deduced from 21-22 February 2014 event. The corresponding observations are presented in Fig. 14 and Fig. 15. The agreement between measured and computed reflectivity values are not as good as for the 20 March event. It should be noted, however, that the agreement during the heavy precipitation period, between 2300 and 0000 UTC, is rather good. The other interesting time period is between just before 2000 UTC and just after $2300 \mathrm{UTC}$, this period is marked by gray shading in the $Z_{d r}$ plot. During this period the $Z_{d r}$ decreases while $F R$ increases. The $Z_{d r}$ computations indicate that this decrease is due to the change in $A R$, which changes from 0.6 to 0.8 during this time period. This pattern is consistent with riming growth of planar crystals, as was hypothesized in the conceptual model. During this period the observed $D_{0}$ values are close to $1 \mathrm{~mm}$, which are also consistent with presence of crystals / rimed crystals.

Often, it is assumed that differential reflectivity and other dual-polarization radar variables should decrease because of riming [Straka et al., 2000; Liu and Chandrasekar, 2000; Giangrande et al., 2016]. The motivation for this is that heavy riming would transform an ice particle to graupel. A graupel particle typically would have an quasi spherical shape and therefore the differential reflectivity will become smaller. The presented analysis indicates that care should be taken while making conclusions about riming presence from the analysis of dual-polarization radar measurements. Since riming growth of aggregates could produce the opposite to the expected pattern.

\section{Discussion and Conclusions}

Following the assumption proposed for a new ice particle property-based microphysical scheme Morrison and Grabowski [2008]; Morrison and Milbrandt [2015], the ice particle rime mass fraction was retrieved from ensemble mean snow density measurements. At the first step of the retrieval, a reference $m(D)$ relation, deviations from which could be interpreted as snowflake mass growth by riming, was determined. The relation represents particles with the masses belonging to the 5 th percentile for a given dimension. The selection of the particles is somewhat arbitrary, but follows a rule that these particles should be the lightest observed. The derived relation $m=0.0053 D_{\max }^{2.05}$ can be treated as a relation of unrimed snowflakes. Since the relation is computed from observations recorded during 22 events that took place in Southern Finland, we cannot exclude potential differences, if one uses it for a characterization of snowfall taking place in a different geographical region. It should also be noted, that the relation is different from ones listed in literature. For example, it gives heavier particles than Brown and Francis [1995], but agrees relatively well with [Heymsfield et al., 2004].

To verify the proposed rime mass fraction retrieval approach, a method to link $F R$ and microwave radiometer liquid water path observations was proposed. Given that the exponent of the retrieved $m(D)$ is very close to 2 , the dependence of the computed effective liquid water path on $D$ can be ignored. The comparison between ELWP and $L W P$ showed that they react to the same processes that take place in the observed precipitation systems. The computed $E L W P$ is about half of $L W P$. There are also differences in timings and appearances of certain features, which could be attributed to the deviation of effective paths of snowflakes from the vertical.

Using the derived rime mass fraction, analysis of riming mass growth effects on snowfall was analyzed. From observations of 22 events, it was found that riming is responsible for $5 \%$ to $40 \%$ of precipitation mass. Furthermore, a correlation between rime precipitation fraction and precipitation accumulation was observed. This correlation, however, is determined by just two events and may not be statistically significant. A much weaker correlation between the average precipitation rate and rime precipitation fraction also points in the di- 
rection that there is no strong link between average precipitation amount and riming for an event.

The comparison of dual-polarization radar observations and retrieved snowflake microphysical properties was also carried out. It was shown that this comparison can be used to test the validity of the conceptual riming model. In this study the conceptual model of [Heymsfield, 1982] was modified slightly by hypothesizing that shapes of aggregates would not change during riming. Therefore, it is expected that $Z_{d r}$ should increase with riming, as was observed on 20 March 2014. For crystals, on the other hand, the opposite is expected and was observed on 21 February between 2000 and 2300 UTC where the $Z_{d r}$ was decreasing while $F R$ was increasing. This behavior is expected to be more common for smaller ice particles. The overall connection between dual-polarization radar observations and riming is therefore expected to be more complex than currently expected. In some cases $Z_{d r}$ will increase while in the other it will decrease, depending on initial particle sizes.

\section{References}

Barthazy, E., and R. Schefold (2006), Fall velocity of snowflakes of different riming degree and crystal types, Atmospheric research, 82(1), 391-398.

Borys, R. D., D. H. Lowenthal, and D. L. Mitchell (2000), The relationships among cloud microphysics, chemistry, and precipitation rate in cold mountain clouds, 34(16), 25932602.

Borys, R. D., D. H. Lowenthal, S. A. Cohn, and W. O. J. Brown (2003), Mountaintop and radar measurements of anthropogenic aerosol effects on snow growth and snowfall rate, Geophysical Research Letters, 30(10), n/a-n/a, doi:10.1029/2002GL016855, 1538.

Brandes, E. A., K. Ikeda, G. Zhang, M. Schönhuber, and R. M. Rasmussen (2007), A statistical and physical description of hydrometeor distributions in colorado snowstorms using a video disdrometer, Journal of applied meteorology and climatology, 46(5), 634-650.

Bringi, V. N., and V. Chandrasekar (2001), Polarimetric Doppler weather radar: principles and applications, Cambridge University Press.

Brown, P. R. A., and P. N. Francis (1995), Improved Measurements of the Ice Water Content in Cirrus Using a Total-Water Probe, Journal of Atmospheric and Oceanic Technology, 12(2), 410-414, doi:10.1175/1520-0426(1995)012<0410:IMOTIW>2.0.CO;2.

Cadeddu, M. P., J. C. Liljegren, and D. D. Turner (2013), The Atmospheric Radiation Measurement (ARM) program network of microwave radiometers: instrumentation, data, and retrievals, Atmos. Meas. Tech., 6(9), 2359-2372, doi:10.5194/amt-6-2359-2013.

Chandrasekar, V., R. Keranen, S. Lim, and D. Moisseev (2013), Recent advances in classification of observations from dual polarization weather radars, Atmospheric Research, 119, 97 - 111, doi:http://dx.doi.org/10.1016/j.atmosres.2011.08.014.

Ellis, S., D. Serke, J. Hubbert, D. Albo, A. Weekley, M. Politovich, A. Gaydos, D. Adriaansen, E. Williams, D. Smalley, and M. Donovan (2012), Towards the detection of aircraft icing conditions using operational dual-polarimetric radar, in Proc. ERAD 2012 The Seventh European Conference On Radar In Meteorology And Hydrology (Toulouse, France, June 2012), pp. 24-29.

Erfani, E., and D. L. Mitchell (2017), Growth of ice particle mass and projected area during riming, Atmospheric Chemistry and Physics, 17(2), 1241-1257, doi:10.5194/ acp-17-1241-2017.

Field, P. R., and A. J. Heymsfield (2015), Importance of snow to global precipitation, Geophysical Research Letters, 42(21), 9512-9520, doi:10.1002/2015GL065497.

Garrett, T. J., and S. E. Yuter (2014), Observed influence of riming, temperature, and turbulence on the fallspeed of solid precipitation, Geophysical Research Letters, 41(18), 65156522, doi:10.1002/2014GL061016.

Giangrande, S. E., T. Toto, A. Bansemer, M. R. Kumjian, S. Mishra, and A. V. Ryzhkov (2016), Insights into riming and aggregation processes as revealed by aircraft, radar, and 
disdrometer observations for a 27 april 2011 widespread precipitation event, Journal of Geophysical Research: Atmospheres, 121(10), 5846-5863, doi:10.1002/2015JD024537, 2015JD024537.

Grazioli, J., G. Lloyd, L. Panziera, C. R. Hoyle, P. J. Connolly, J. Henneberger, and A. Berne (2015), Polarimetric radar and in situ observations of riming and snowfall microphysics during CLACE 2014, Atmospheric Chemistry and Physics, 15(23), 13,787-13,802, doi: 10.5194/acp-15-13787-2015.

Harimaya, T., and M. Sato (1989), Measurement of the riming amount on snowflakes, J. Fac. Sci., Hokkaido Univ., 8(4), 355-366.

Heymsfield, A. J. (1982), A comparative study of the rates of development of potential graupel and hail embryos in high plains storms, Journal of the Atmospheric Sciences, 39(12), 2867-2897, doi:10.1175/1520-0469(1982)039<2867:ACSOTR>2.0.CO;2.

Heymsfield, A. J., A. Bansemer, C. Schmitt, C. Twohy, and M. R. Poellot (2004), Effective Ice Particle Densities Derived from Aircraft Data, Journal of the Atmospheric Sciences, 61(9), 982-1003, doi:10.1175/1520-0469(2004)061<0982:EIPDDF>2.0.CO;2.

Hobbs, P. V. (1978), Organization and structure of clouds and precipitation on the mesoscale and microscale in cyclonic storms, Reviews of Geophysics, 16(4), 741-755, doi:10.1029/ RG016i004p00741.

Hobbs, P. V., S. Chang, and J. D. Locatelli (1974), The dimensions and aggregation of ice crystals in natural clouds, Journal of Geophysical Research, 79(15), 2199-2206, doi:10. 1029/JC079i015p02199.

Hogan, R. J., P. N. Francis, H. Flentje, A. J. Illingworth, M. Quante, and J. Pelon (2003), Characteristics of mixed-phase clouds. i: Lidar, radar and aircraft observations from clare'98, Quarterly Journal of the Royal Meteorological Society, 129(592), 2089-2116, doi:10.1256/rj.01.208.

Hogan, R. J., L. Tian, P. R. A. Brown, C. D. Westbrook, A. J. Heymsfield, and J. D. Eastment (2012), Radar scattering from ice aggregates using the horizontally aligned oblate spheroid approximation, Journal of Applied Meteorology and Climatology, 51(3), 655671, doi:10.1175/JAMC-D-11-074.1.

Kajikawa, M. (1989), Observation of the falling motion of early snowflakes .2. on the variation of falling velocity, Journal of the meteorological society of Japan, 67(5), 731-738.

Kalesse, H., W. Szyrmer, S. Kneifel, P. Kollias, and E. Luke (2016), Fingerprints of a riming event on cloud radar doppler spectra: observations and modeling, Atmospheric Chemistry and Physics, 16(5), 2997-3012, doi:10.5194/acp-16-2997-2016.

Kneifel, S., A. von Lerber, J. Tiira, D. Moisseev, P. Kollias, and J. Leinonen (2015), Observed relations between snowfall microphysics and triple-frequency radar measurements, Journal of Geophysical Research: Atmospheres, 120(12), 6034-6055, doi: 10.1002/2015JD023156, 2015JD023156.

Leinonen, J. (2014), High-level interface to t-matrix scattering calculations: architecture, capabilities and limitations, Opt. Express, 22(2), 1655-1660, doi:10.1364/OE.22.001655

Leinonen, J., D. Moisseev, M. Leskinen, and W. A. Petersen (2012), A climatology of disdrometer measurements of rainfall in Finland over five years with implications for global radar observations, Journal of Applied Meteorology and Climatology, 51(2), 392-404, doi:10.1175/JAMC-D-11-056.1.

Liu, H., and V. Chandrasekar (2000), Classification of hydrometeors based on polarimetric radar measurements: Development of fuzzy logic and neuro-fuzzy systems, and in situ verification, Journal of Atmospheric and Oceanic Technology, 17(2), 140-164, doi:10. 1175/1520-0426(2000)017<0140:COHBOP>2.0.CO;2.

Locatelli, J. D., and P. V. Hobbs (1974), Fall speeds and masses of solid precipitation particles, Journal of Geophysical Research, 79(15), 2185-2197.

Lohmann, U. (2004), Can anthropogenic aerosols decrease the snowfall rate?, Journal of the Atmospheric Sciences, 61(20), 2457-2468, doi:10.1175/1520-0469(2004)061<2457: CAADTS $>2.0 . \mathrm{CO} ; 2$. 
Magono, C., and T. Nakamura (1965), Aerodynamic Studies of Falling Snowflakes, Journal of the Meteorological Society of Japan. Ser. II, 43(3), 139-147.

Matejka, T. J., R. A. Houze, and P. V. Hobbs (1980), Microphysics and dynamics of clouds associated with mesoscale rainbands in extratropical cyclones, Quarterly Journal of the Royal Meteorological Society, 106(447), 29-56, doi:10.1002/qj.49710644704.

Matrosov, S. Y., A. J. Heymsfield, and Z. Wang (2005), Dual-frequency radar ratio of nonspherical atmospheric hydrometeors, Geophysical Research Letters, 32(13), n/a-n/a, doi: 10.1029/2005GL023210, 113816.

Mishchenko, M. I., and L. D. Travis (1994), T-matrix computations of light scattering by large spheroidal particles, Optics Communications, 109(1), 16 - 21, doi:http://dx.doi.org/ 10.1016/0030-4018(94)90731-5.

Mitchell, D. L. (1996), Use of Mass- and Area-Dimensional Power Laws for Determining Precipitation Particle Terminal Velocities, J. Atmos. Sci., 53(12), 1710-1723, doi:10.1175/ 1520-0469(1996)053<1710:UOMAAD>2.0.CO;2.

Mitchell, D. L., R. Zhang, and R. L. Pitter (1990), Mass-Dimensional Relationships for Ice Particles and the Influence of Riming on Snowfall Rates, J. Appl. Meteor., 29(2), 153-163, doi:10.1175/1520-0450(1990)029<0153:MDRFIP>2.0.CO;2.

Moisseev, D. N., and V. Chandrasekar (2007), Examination of the $\mu-\Lambda$ Relation Suggested for Drop Size Distribution Parameters, J. Atmos. Oceanic Technol., 24(5), 847-855, doi: 10.1175/JTECH2010.1.

Moisseev, D. N., S. Lautaportti, J. Tyynela, and S. Lim (2015), Dual-polarization radar signatures in snowstorms: Role of snowflake aggregation, Journal of Geophysical Research: Atmospheres, 120(24), 12,644-12,655, doi:10.1002/2015JD023884, 2015JD023884.

Morrison, H., and W. W. Grabowski (2008), A novel approach for representing ice microphysics in models: Description and tests using a kinematic framework, Journal of the Atmospheric Sciences, 65(5), 1528-1548, doi:10.1175/2007JAS2491.1.

Morrison, H., and J. A. Milbrandt (2015), Parameterization of Cloud Microphysics Based on the Prediction of Bulk Ice Particle Properties. Part I: Scheme Description and Idealized Tests, J. Atmos. Sci., 72(1), 287-311, doi:10.1175/JAS-D-14-0065.1.

Mosimann, L. (1995), An improved method for determining the degree of snow crystal riming by vertical doppler radar, Atmospheric Research, 37(4), 305 - 323, doi:http: //dx.doi.org/10.1016/0169-8095(94)00050-N.

Mosimann, L., E. Weingartner, and A. Waldvogel (1994), An analysis of accreted drop sizes and mass on rimed snow crystals, Journal of the Atmospheric Sciences, 5l(11), 15481558, doi:10.1175/1520-0469(1994)051<1548:AAOADS > 2.0.CO;2.

Moss, S., and D. Johnson (1994), Aircraft measurements to validate and improve numerical model parametrisations of ice to water ratios in clouds, Atmospheric Research, 34(1), 1 25, doi:http://dx.doi.org/10.1016/0169-8095(94)90078-7.

Petäjä, T., E. J. O’Connor, D. Moisseev, V. A. Sinclair, A. J. Manninen, R. Väänänen, A. von Lerber, J. A. Thornton, K. Nicoll, W. Petersen, V. Chandrasekar, J. N. Smith, P. M. Winkler, O. Krüger, H. Hakola, H. Timonen, D. Brus, T. Laurila, E. Asmi, M.-L. Riekkola, L. Mona, P. Massoli, R. Engelmann, M. Komppula, J. Wang, C. Kuang, J. Bäck, A. Virtanen, J. Levula, M. Ritsche, and N. Hickmon (2016), BAECC A field campaign to elucidate the impact of Biogenic Aerosols on Clouds and Climate, Bull. Amer. Meteor. Soc., doi: 10.1175/BAMS-D-14-00199.1.

Pruppacher, H., and J. Klett (1996), Microphysics of Clouds and Precipitation, Atmospheric and Oceanographic Sciences Library, Springer Netherlands.

Ryzhkov, A., P. Zhang, H. Reeves, M. Kumjian, T. Tschallener, S. Trömel, and C. Simmer (2016), Quasi-vertical profiles-a new way to look at polarimetric radar data, Journal of Atmospheric and Oceanic Technology, 33(3), 551-562, doi:10.1175/JTECH-D-15-0020.1.

Saleeby, S. M., W. R. Cotton, D. Lowenthal, and J. Messina (2013), Aerosol impacts on the microphysical growth processes of orographic snowfall, Journal of Applied Meteorology and Climatology, 52(4), 834-852, doi:10.1175/JAMC-D-12-0193.1. 
Shupe, M. D., S. Y. Matrosov, and T. Uttal (2006), Arctic Mixed-Phase cloud properties derived from Surface-Based sensors at SHEBA, Journal of the Atmospheric Sciences, 63(2), 697,711, doi:10.1175/JAS3659.1.

Sihvola, A. (1999), Electromagnetic mixing formulas and applications, London : Institution of Electrical Engineers.

Straka, J., D. Zrnić, and A. Ryzhkov (2000), Bulk hydrometeor classification and quantification using polarimetric radar data: Synthesis of relations, Journal of Applied ..., 39, doi:10.1175/1520-0450(2000)039<1341:BHCAQU>2.0.CO;2.

Tiira, J., D. N. Moisseev, A. von Lerber, D. Ori, A. Tokay, L. F. Bliven, and W. Petersen (2016), Ensemble mean density and its connection to other microphysical properties of falling snow as observed in southern finland, Atmospheric Measurement Techniques, 9(9), 4825-4841, doi:10.5194/amt-9-4825-2016.

Westbrook, C. D., and A. J. Illingworth (2011), Evidence that ice forms primarily in supercooled liquid clouds at temperatures > ấS $27^{\circ} \mathrm{c}$, Geophysical Research Letters, 38(14), n/a-n/a, doi:10.1029/2011GL048021, 114808.

Westbrook, C. D., R. C. Ball, P. R. Field, and A. J. Heymsfield (2004), Universality in snowflake aggregation, Geophysical Research Letters, 31(15), n/a-n/a, doi:10.1029/ 2004GL020363, 115104.

Wielaard, D. J., M. I. Mishchenko, A. Macke, and B. E. Carlson (1997), Improved t-matrix computations for large, nonabsorbing and weakly absorbing nonspherical particles and comparison with geometrical-optics approximation, Appl. Opt., 36(18), 4305-4313, doi: 10.1364/AO.36.004305.

Wood, N. B., T. S. L'Ecuyer, F. L. Bliven, and G. L. Stephens (2013), Characterization of video disdrometer uncertainties and impacts on estimates of snowfall rate and radar reflectivity, Atmospheric Measurement Techniques, 6(12), 3635-3648, doi:10.5194/ amt-6-3635-2013.

Zawadzki, I., E. Jung, and G. Lee (2010), Snow Studies. Part I: A Study of Natural Variability of Snow Terminal Velocity, J. Atmos. Sci., 67(5), 1591-1604, doi:10.1175/ 2010JAS3342.1.

\section{Acknowledgments}

We would like to acknowledge the Hyytiälä station and University of Helsinki personnel for the daily tasks with measurements, especially mentioning Matti Leskinen and Janne Levula. The research of JT and DM was supported by Academy of Finland (grant 305175) and the Academy of Finland Finnish Center of Excellence program (grant 272041). AvL was funded by grant of the Vilho, Yrjö and Kalle Väisälä Foundation and by SESAR Joint Undertaking Horizon 2020 grant agreement No 699221 (PNOWWA). The instrumentation used in this study was supported by NASA Global Precipitation Measurement Mission ground validation program and by the Office of Science U.S. Department of Energy ARM program. The BAECC data used in this study is available from DOE ARM archives. The data from winter 2014/2015 is available by request from the first author (dmitri.moisseev@ helsinki.fi). 


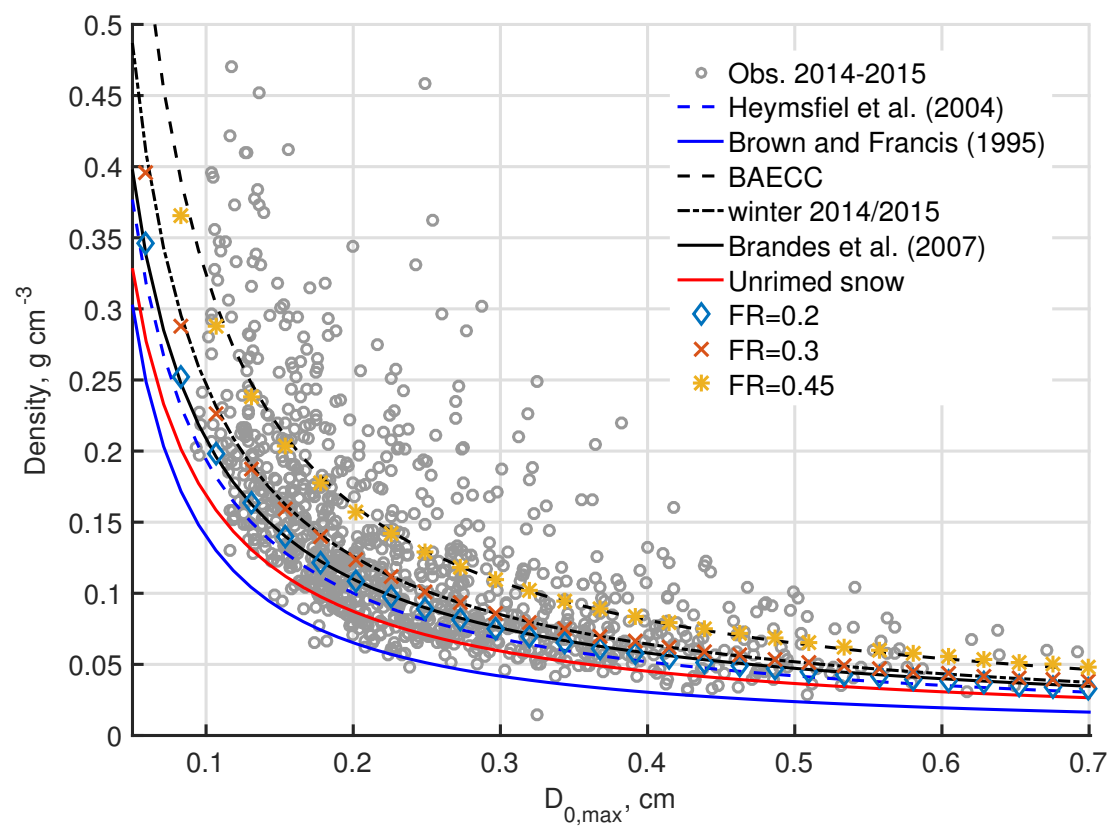

Figure 1. Scatter plot of volume flux weighted ensemble mean snow density, $\rho$, versus median volume diameter $D_{0}$ as retrieved by Tiira et al. [2016]. For the comparison, computed mean snow density - $D_{0}$ curves based on m-D relations of [Brown and Francis, 1995] (blue solid line) and [Heymsfield et al., 2004] (blue dashed line), and [Brandes et al., 2007] (black solid line) $\rho-D_{0}$ relation are also plotted. The black dashed and dot-dashed lines depict $\rho \quad-\quad D_{0}$ relations found for BAECC and 2014/2015 winters. The blue diamonds, red crosses and yellow stars show relations for rime mass fraction, $F R$, values of $0.2,0.3$ and 0.45 respectively. 


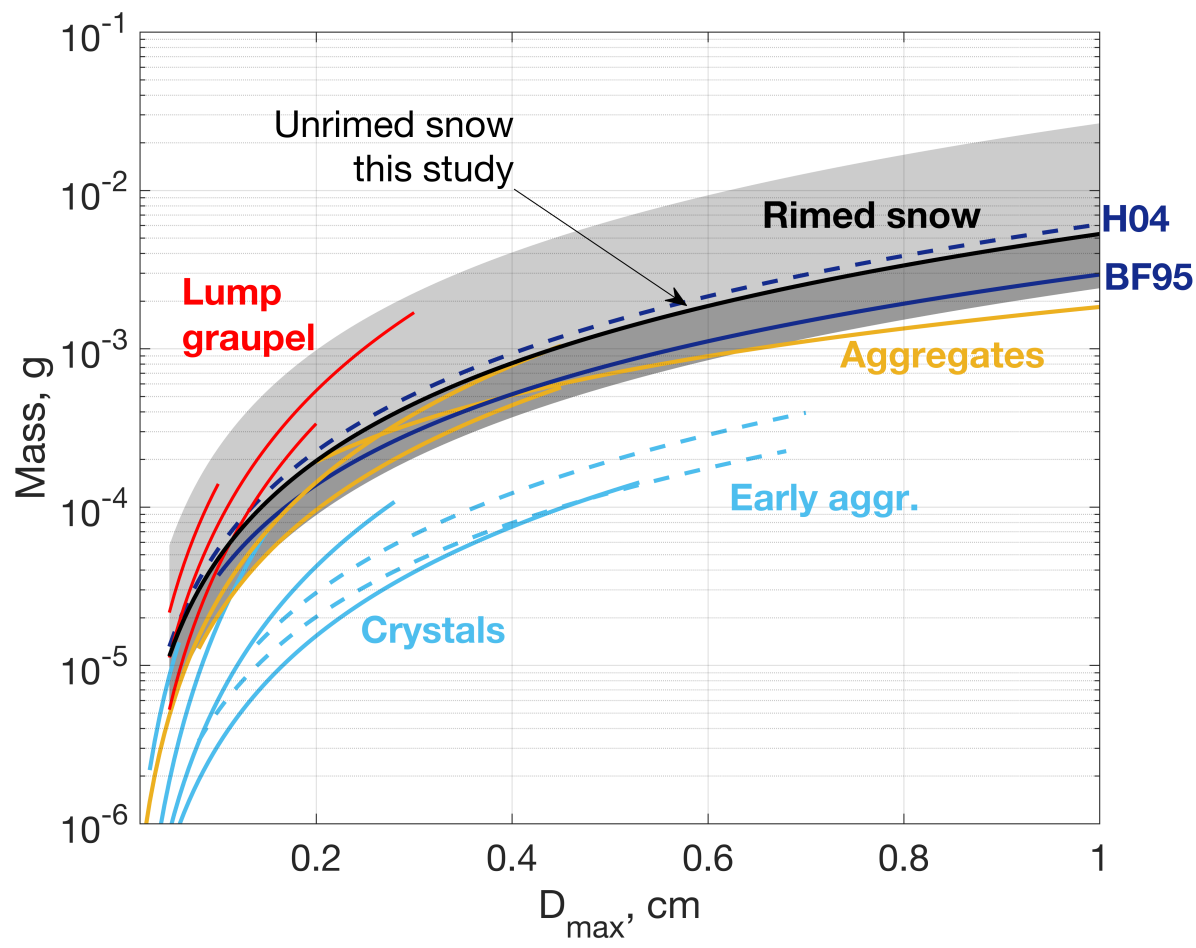

Figure 2. The $m(D)$ relations reported in literature are shown by lines, light blue lines show relations for crystals and early aggregates, yellow lines for aggregates and red lines for graupel. The dark gray shaded region presents the ad hoc $m(D)$ region representative of aggregates. The light gray region depicts the region of rimed particles as retrieved in this study. Two dark blue lines are [Heymsfield et al., 2004] and [Brown and Francis, 1995] relations which are also used in Fig. 1. 

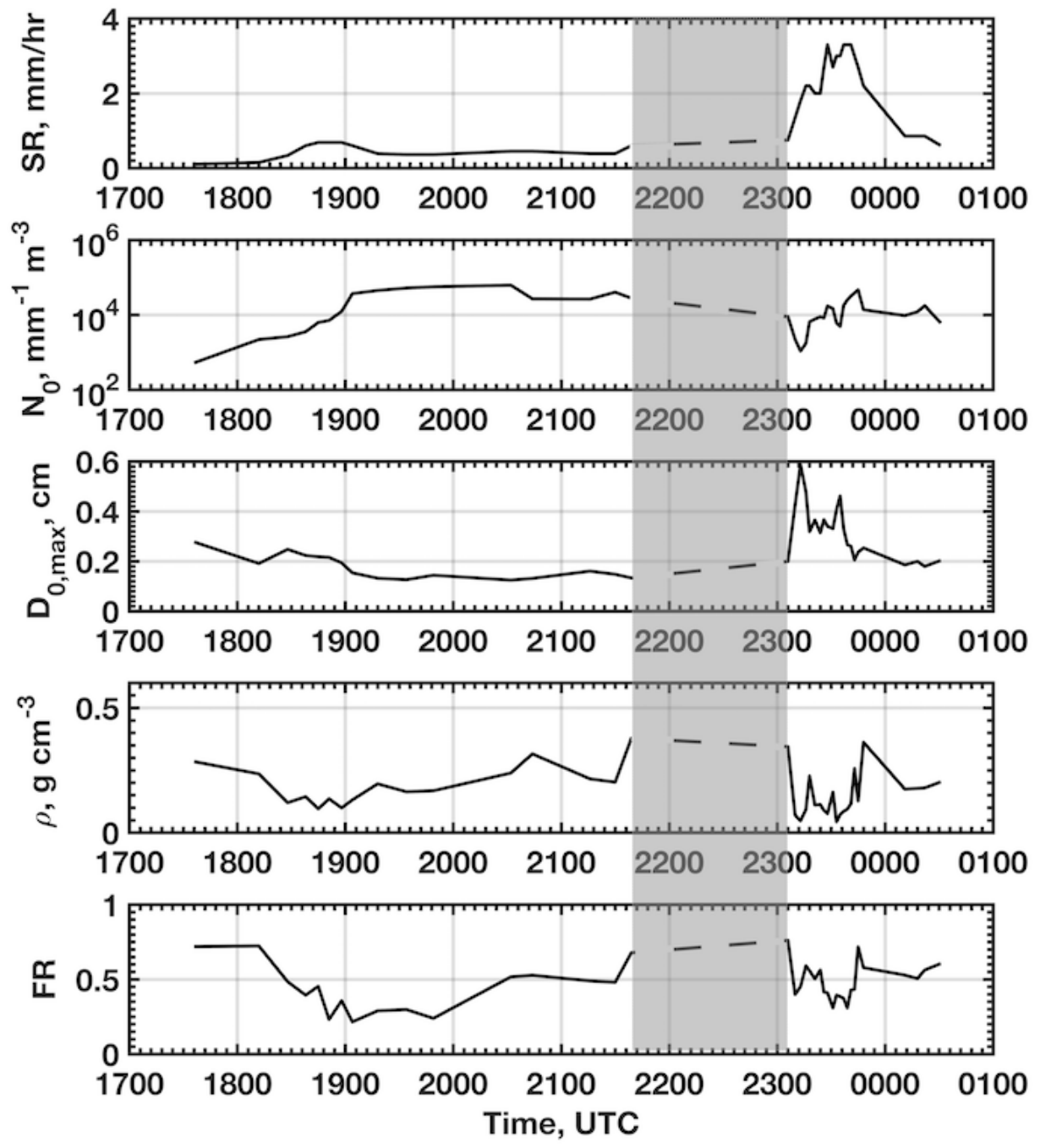

Figure 3. Overview of the precipitation event that took place on February 21 2014. The panels show measurements of snowfall LWE rate, $S R$, PSD intercept parameter, $N_{0}$, median volume diameter, $D_{0}$, bulk density, $\rho$, and rime mass fraction, $F R$. The shaded area shows the time period during which the precipitation rate was low and the density and correspondingly $F R$ retrieval was not stable. 

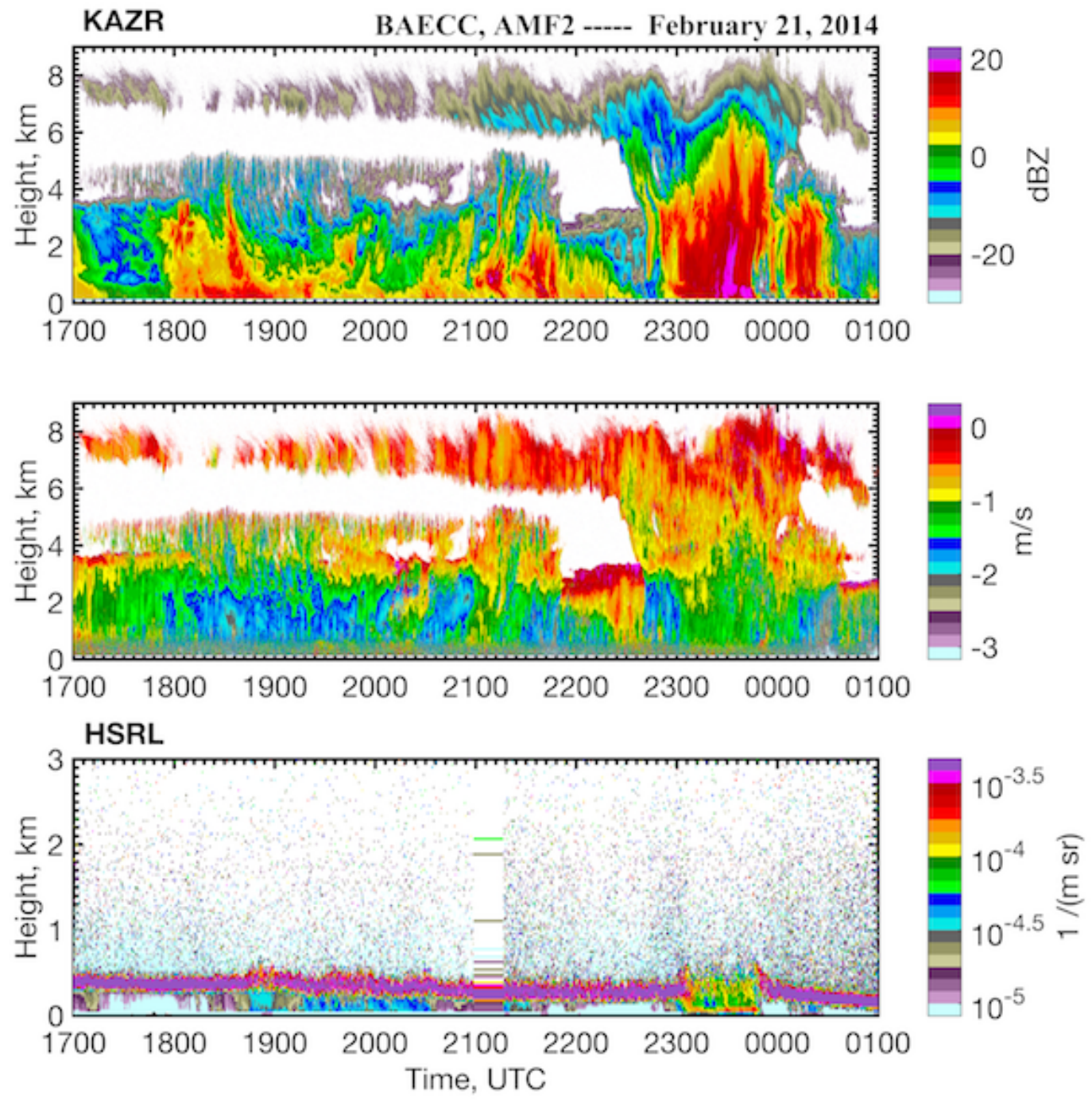

Figure 4. KAZR reflectivity and Doppler velocity, and HSRL measurements for February 21-22 2014 

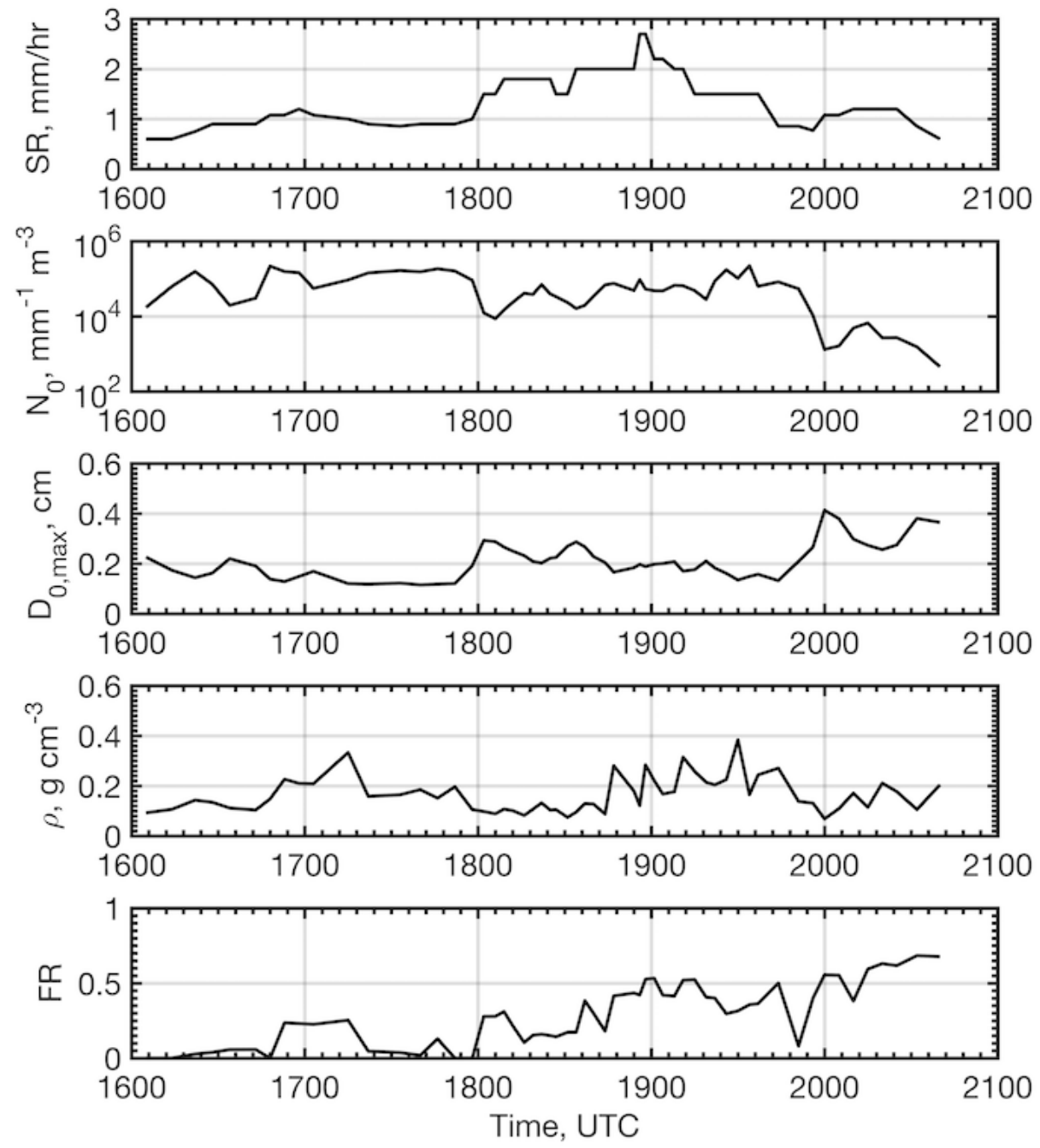

Figure 5. Similar to Fig. 3 but for March 202014. 

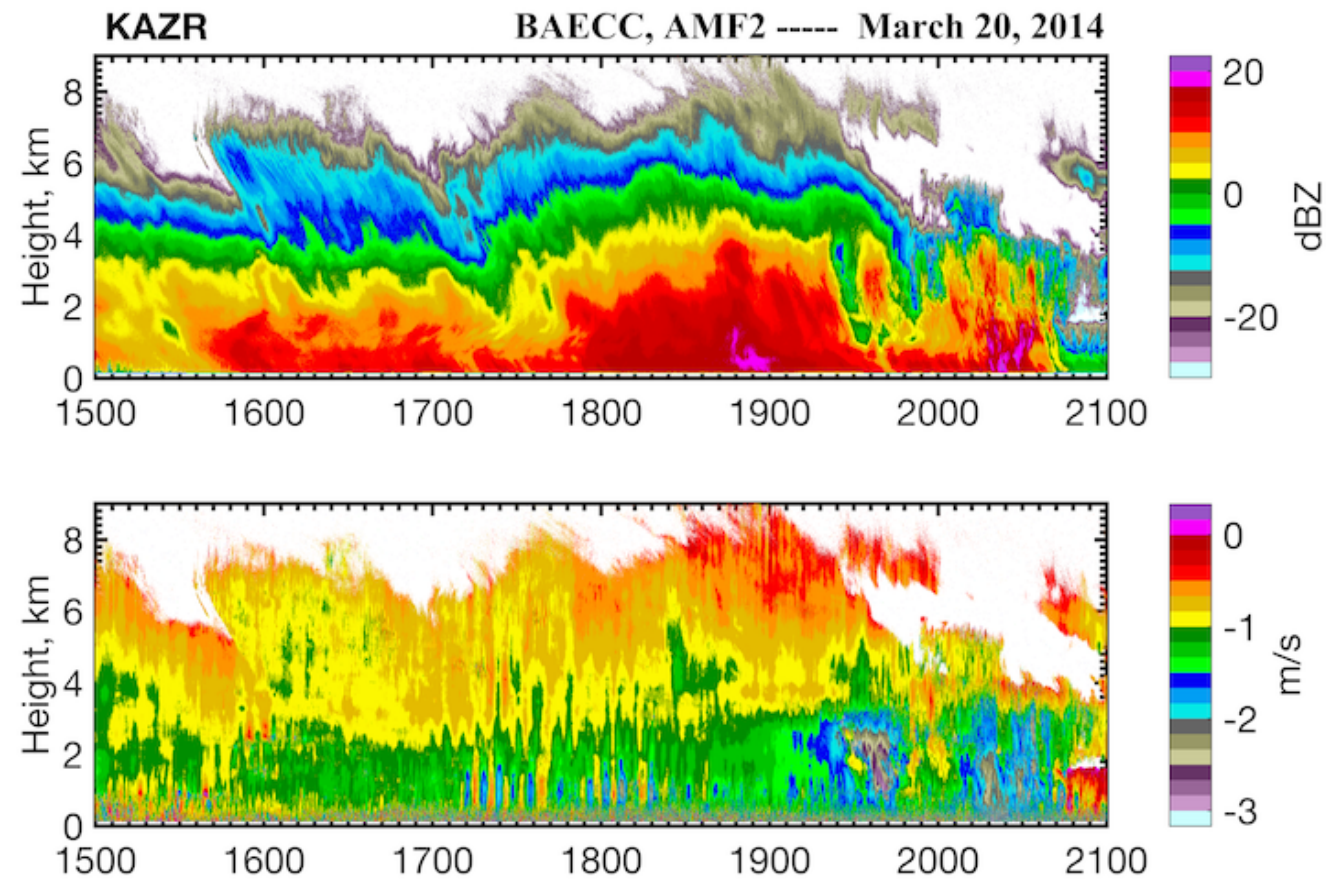

HSRL

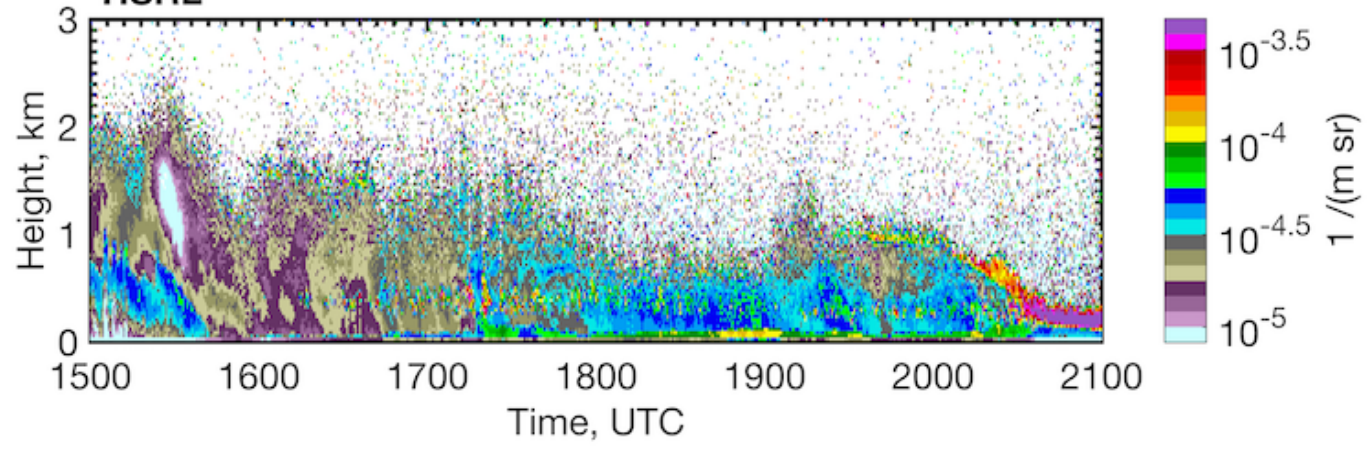

Figure 6. KAZR reflectivity and Doppler velocity, and HSRL measurements for March 202014 event. 

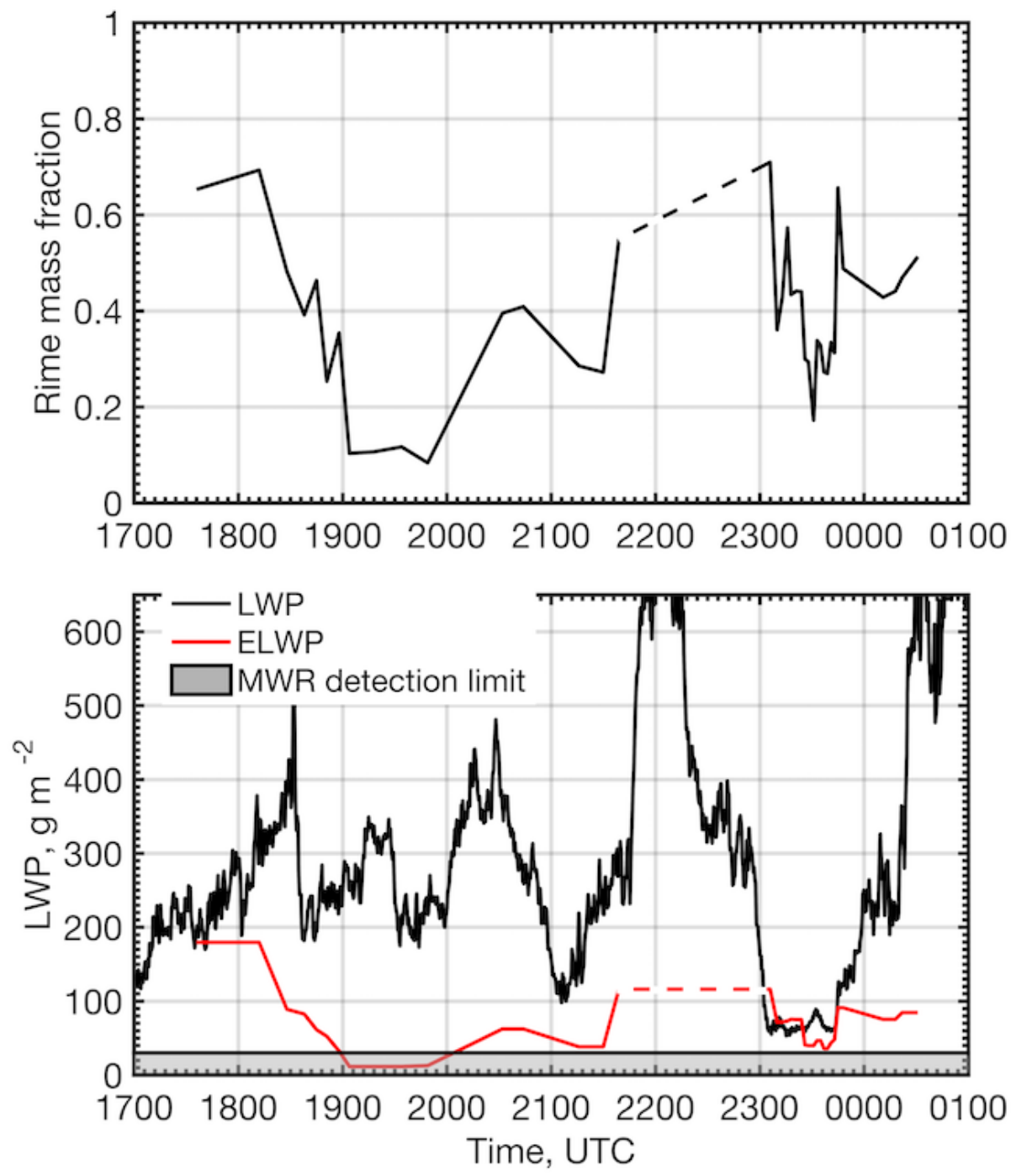

Figure 7. Comparison of rime mass fraction, $F R$, derived effective liquid water path $(E L W P)$ and microwave radiometer measured $L W P$ for the event of 21-21 February 2014. 

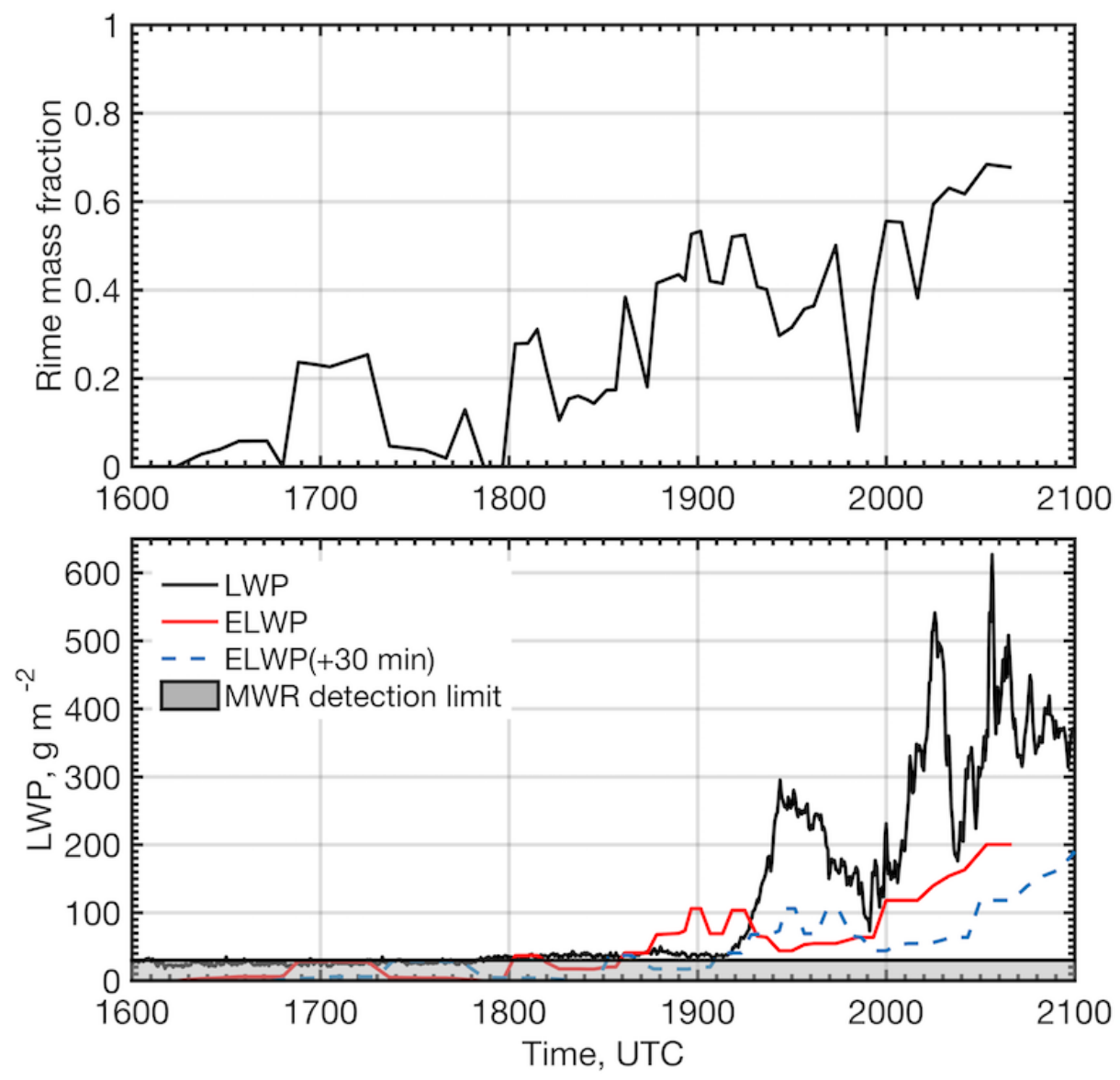

Figure 8. Same as 7 but for the event of 20 March 2014. 

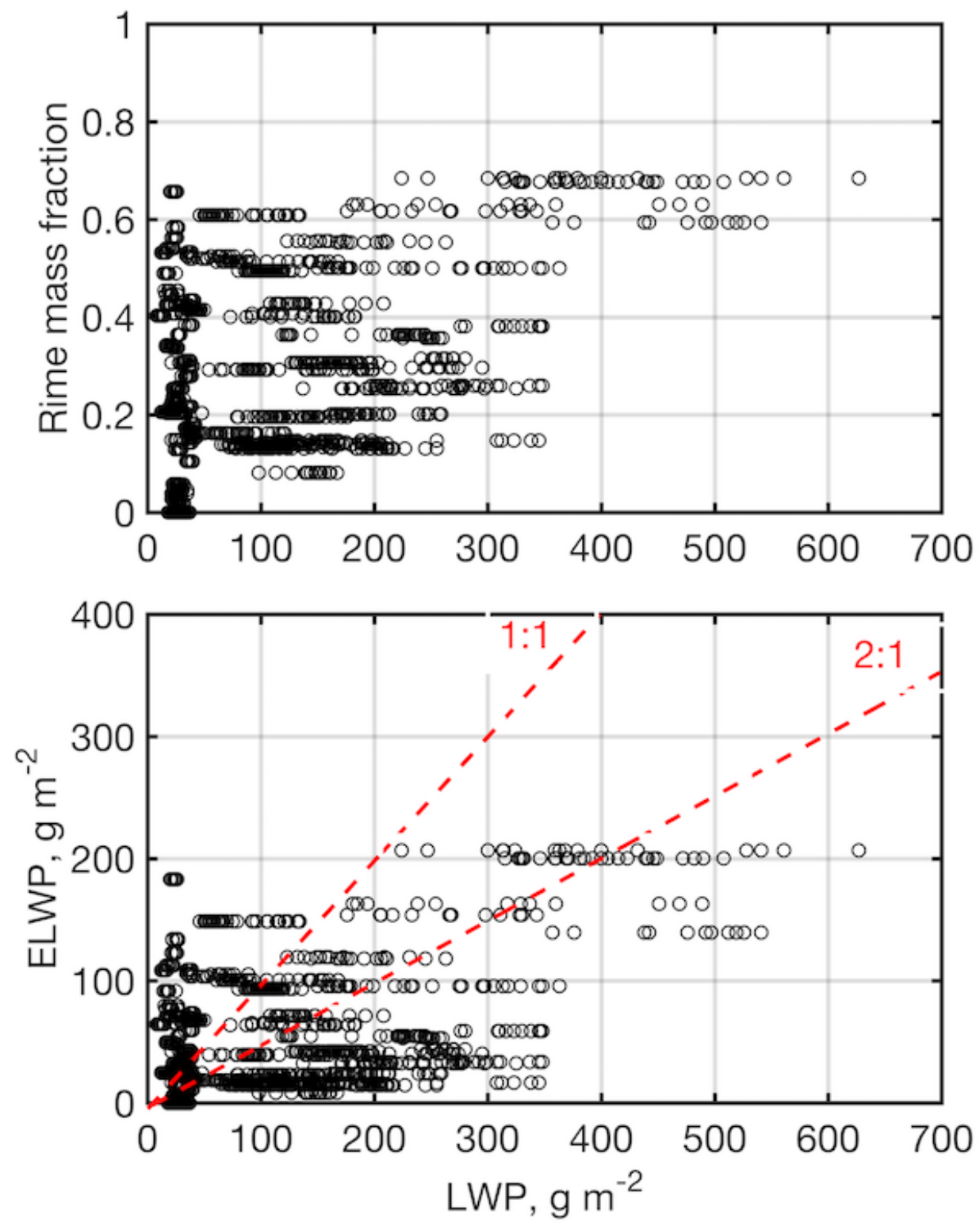

Figure 9. Scatter plots of $F R$ vs. $L W P$ and $E L W P$ vs $L W P$ for all BAECC events. 


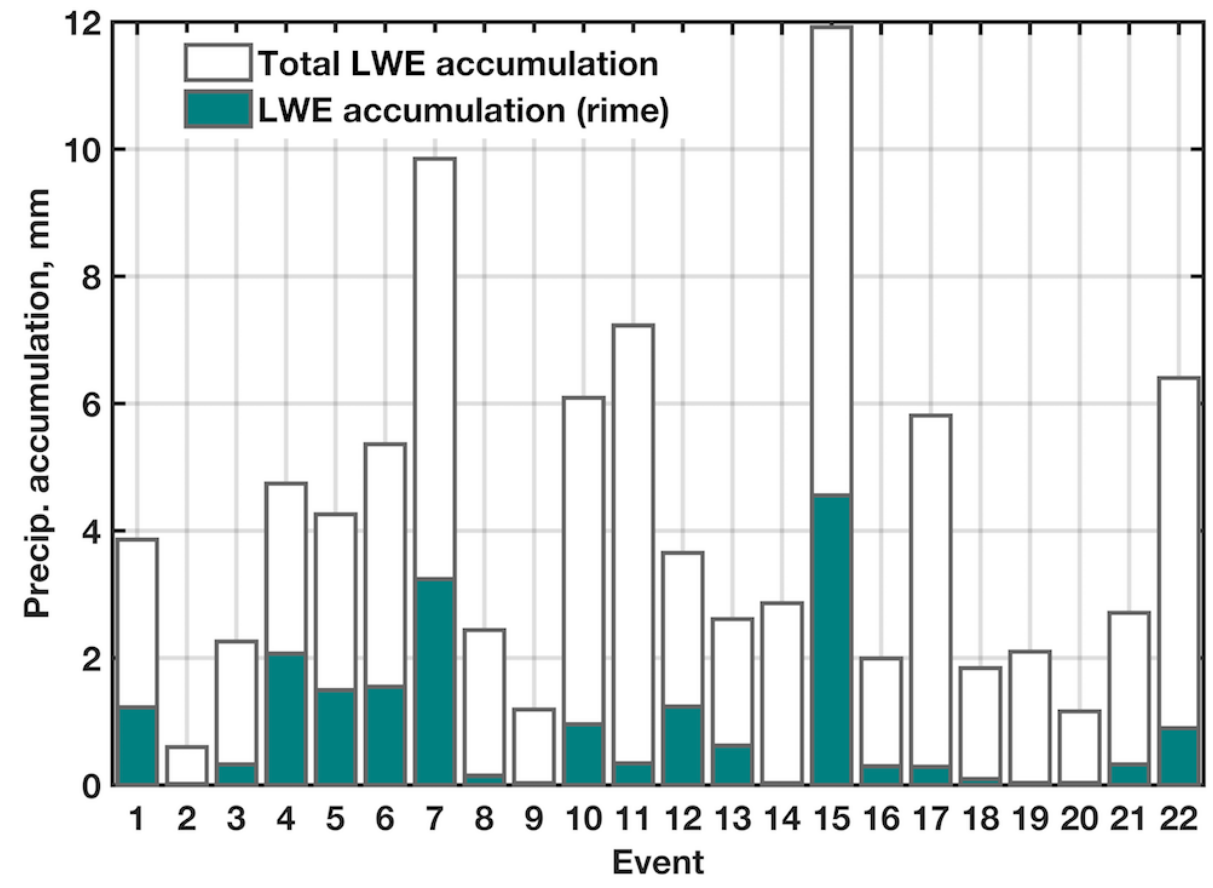

Figure 10. Precipitation liquid water equivalent (LWE) accumulations and rime precipitation fractions for all analyzed events.
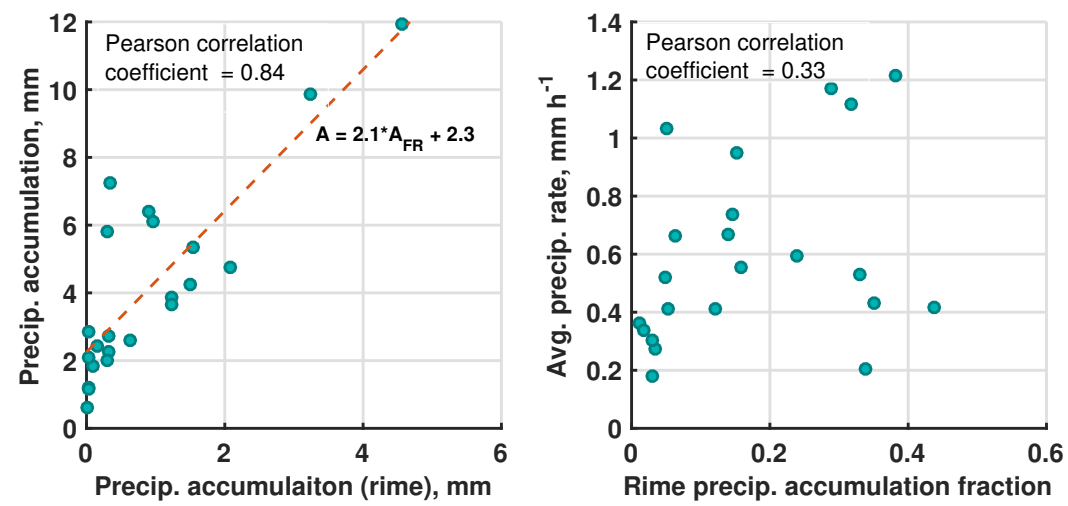

Figure 11. Scatter plots showing relations between rime precipitation accumulation and precipitation accumulations (left panel), rime precipitation accumulation fraction and average precipitation rate (right panel). 
IKAALINEN - vert. profiles from RHI --- March 20, 2014
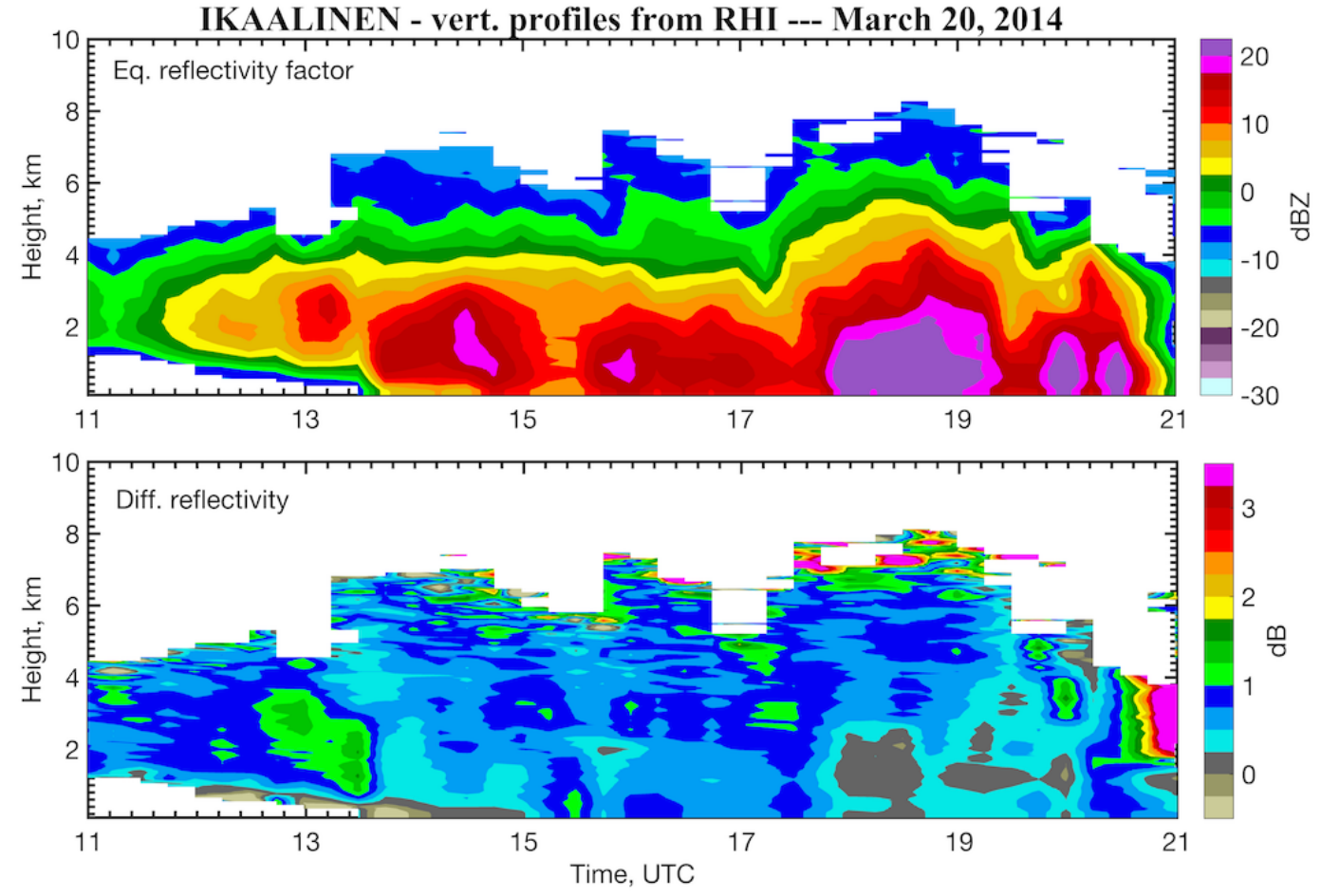

Figure 12. Ikaalinen radar VPT plots of reflectivity and differential reflectivity for 20th March 2014 case. The VPT plots are generated from the RHI scans that were carried out every $15 \mathrm{~min}$. 

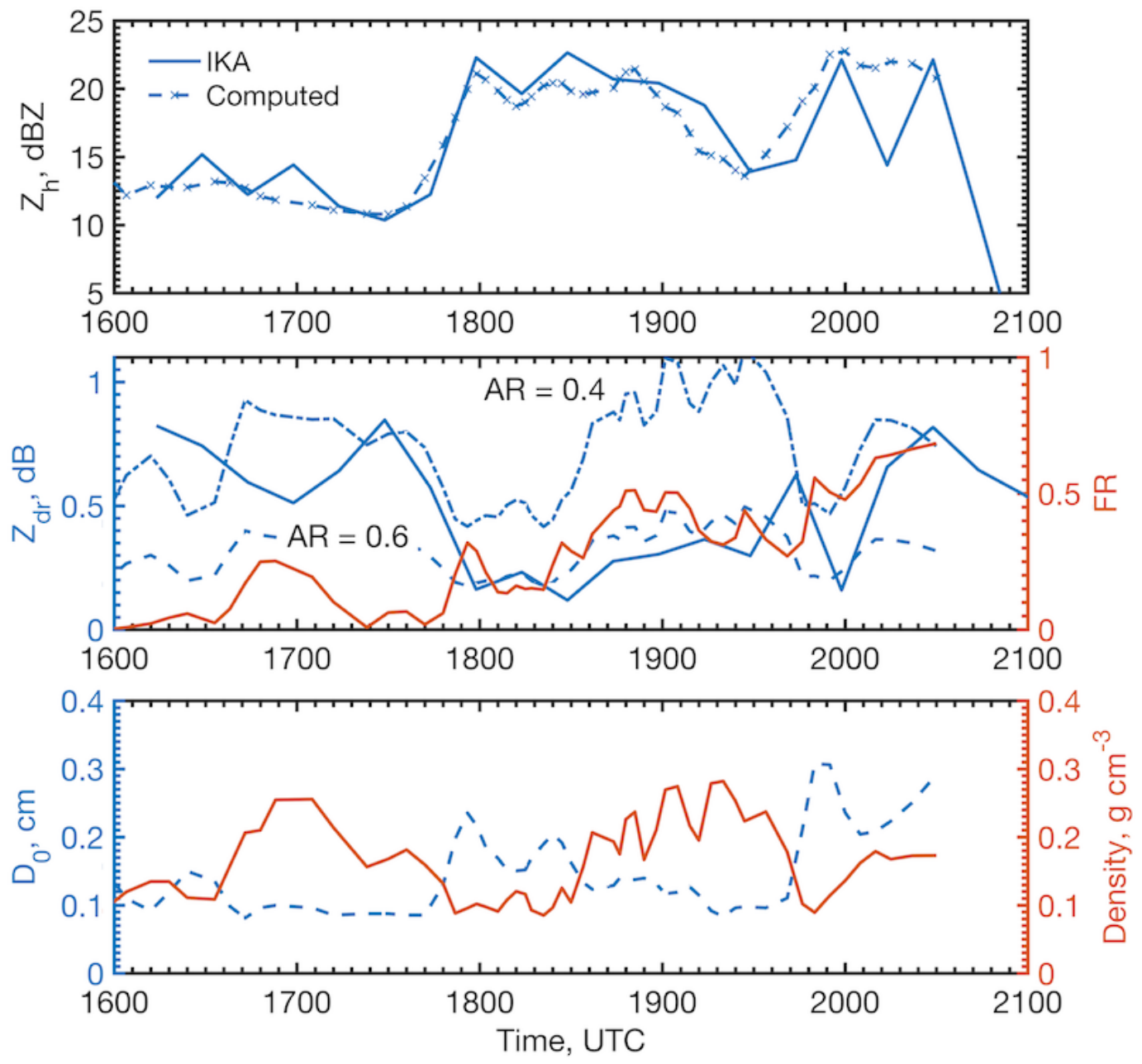

Figure 13. Comparison of $Z_{d r}, F R, D_{0}$ and ensemble mean density. The $Z_{d r}$ time-series are taken from the lowest reliable height, which is about $500 \mathrm{~m}$ above the measurement station. 

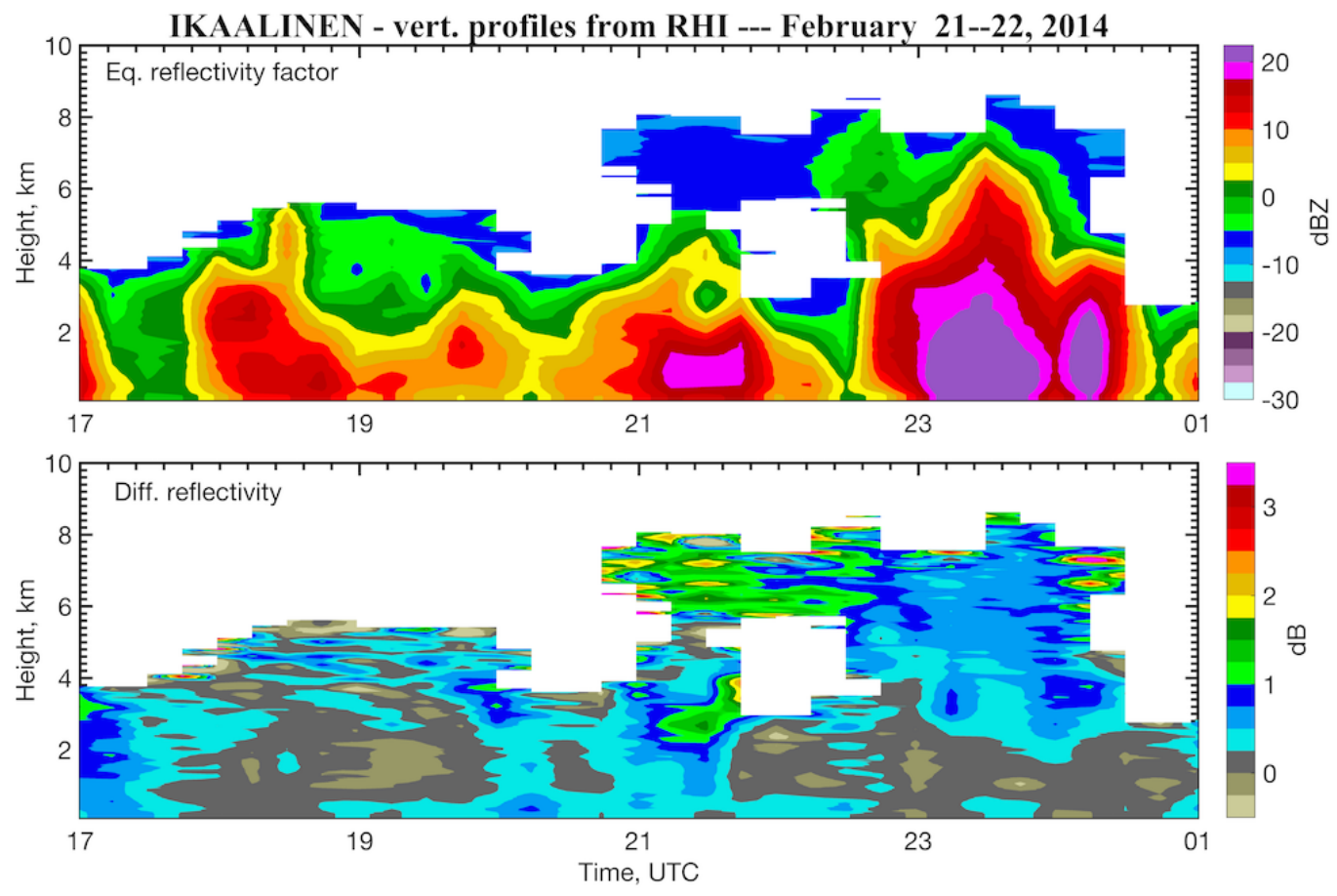

Figure 14. Same as Fig. 12 but for the case of 21st February 2014. 

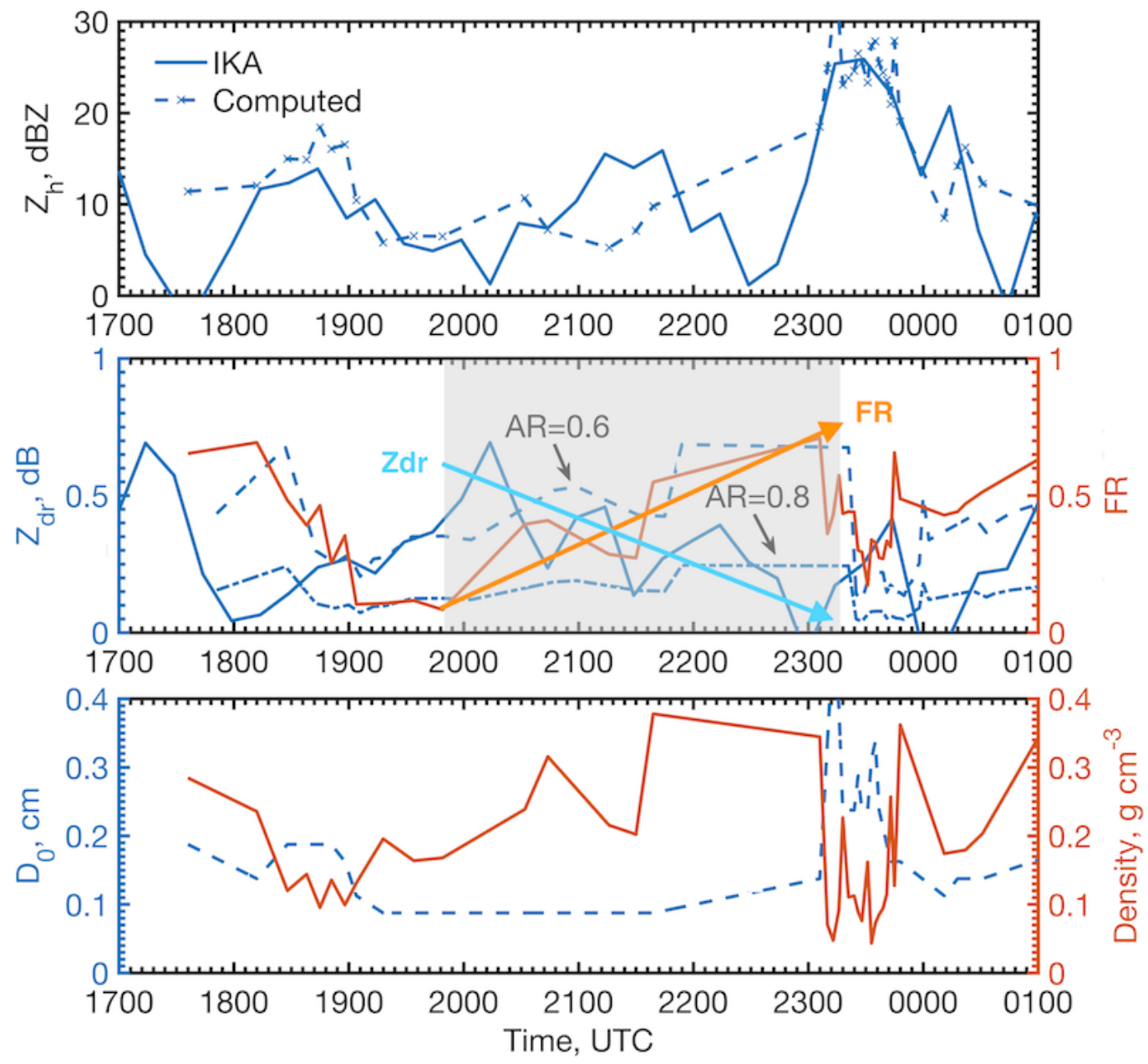

Figure 15. Same as Fig. 13 but for 21 February 2014. The gray shading shows the time where graupel growth is detected, $Z_{d r}$ decreases while $F R$ increases. 
Table 1. Schematic summary of riming growth stages and expected changes in particle maximum dimension, $D_{\max }$, and aspect ratio, $A R$.

\begin{tabular}{|c|c|c|}
\hline & Crystal & Aggregate \\
\hline \multirow{2}{*}{ Stage 0 } & Crystal formation and growth \\
\cline { 2 - 3 } & - & Aggregation \\
\hline
\end{tabular}

\begin{tabular}{|l|l|l|}
\hline \multirow{2}{*}{ Stage 1} & \multicolumn{2}{|c|}{ Riming: Fill-in stage } \\
\cline { 2 - 3 } & $\begin{array}{l}D_{\max } \text { is preserved } \\
A R \text { increases }\end{array}$ & $D_{\max }$ and $A R$ are preserved \\
\hline \multirow{2}{*}{ Stage 2} & \multicolumn{2}{|c|}{ Riming: Graupel growth stage } \\
\cline { 2 - 2 } & $D_{\max }$ increases & $D_{\max }$ and $A R$ increase \\
\hline
\end{tabular}

Table 2. Summary of the studied events. For each event a total LWE accumulation, minimum and maximum temperatures are given. The first six events were recorded during the BAECC experiment.

\begin{tabular}{llccc}
\hline Event & Date & $\begin{array}{c}\text { LWE } \\
\mathrm{mm}\end{array}$ & $\begin{array}{c}T_{\min } \\
{ }^{\circ} \mathrm{C}\end{array}$ & $\begin{array}{c}T_{\max } \\
{ }^{\circ} \mathrm{C}\end{array}$ \\
\hline 1 & 2014 Feb 01 00:00 - 03:30 & 3.9 & -9.8 & -8.9 \\
2 & 2014 Feb 12 05:30 - 07:45 & 0.6 & -1 & 0 \\
3 & 2014 Feb 15 21:50 - Feb 16 01:00 & 2.3 & -2.1 & -1 \\
4 & 2014 Feb 21 17:30 - Feb 22 05:00 & 4.7 & -2.7 & 0 \\
5 & 2014 Mar 18 08:50 - 18:45 & 4.3 & -3.8 & -1.8 \\
6 & 2014 Mar 20 16:05 - 20:40 & 5.4 & -4.3 & -1.3 \\
\hline 7 & 2014 Nov 06 19:15 - Nov 07 13:50 & 9.9 & -2.4 & -1.6 \\
8 & 2014 Dec 18 15:00 - 18:40 & 2.4 & -2.3 & -0.8 \\
9 & 2014 Dec 24 08:45 - 12:45 & 1.2 & -9.2 & -8.9 \\
10 & 2014 Dec 30 02:50 - 13:50 & 6.1 & -10.4 & -0.6 \\
11 & 2015 Jan 3 09:35 - 23:30 & 7.2 & -3.9 & 0 \\
12 & 2015 Jan 7 02:00 - 20:00 & 3.7 & -6.5 & -0.8 \\
13 & 2015 Jan 8 09:00 - 13:30 & 2.6 & -1.9 & 0 \\
14 & 2015 Jan 9 19:55 - Jan 10 03:50 & 2.9 & -3.7 & -0.2 \\
15 & 2015 Jan 12 22:00 - Jan 13 07:50 & 11.9 & -15.7 & -9.0 \\
16 & 2015 Jan 14 02:15 - Jan 14 04:20 & 2.0 & -8.0 & -0.3 \\
17 & 2015 Jan 16 01:50 - 07:30 & 5.8 & -1.3 & -0.6 \\
18 & 2015 Jan 18 16:15 - 20:45 & 1.8 & -2.4 & -0.3 \\
19 & 2015 Jan 22 21:15 - Jan 23 03:30 & 2.1 & -13.3 & -12.5 \\
20 & 2015 Jan 23 16:00 - 22:30 & 1.2 & -10.1 & -8.8 \\
21 & 2015 Jan 25 09:00 - 15:45 & 2.7 & -2.4 & -1.7 \\
22 & 2015 Jan 31 13:40 - Jan 31 23:15 & 6.4 & -1.9 & -0.4 \\
\hline
\end{tabular}

